\title{
Parental trophic exposure to three aromatic fractions of polycyclic aromatic hydrocarbons in the zebrafish: Consequences for the offspring
}

\author{
Perrichon Prescilla ${ }^{1,2,{ }^{*}}$, Akcha Farida ${ }^{1}$, Le Menach Karyn ${ }^{3}$, Goubeau Manon ${ }^{1}$, Budzinski Helene ${ }^{3}$, \\ Cousin Xavier ${ }^{1,4}$, Bustamante Paco ${ }^{2}$
}

1 IFREMER, Lab Ecotoxicol, Lhoumeau Nantes, France.

2 Univ La Rochelle, Littoral Environm \& Soc LIENSs, CNRS, UMRi 7266, F-17042 La Rochelle 01, France.

${ }^{3}$ Univ Bordeaux, EPOC, LPTC, UMR CNRS 5805, F-33405 Talence, France.

${ }^{4}$ INRA, Lab Physiol \& Genom Poisons, F-35042 Rennes, France.

*Corresponding author : Prescilla Perrichon, email address : prescilla.perrichon@gmail.com

\begin{abstract}
:
In recent decades, $\mathrm{PAH}$ emissions due to extensive anthropogenic activities have risen sharply causing considerable pollution of aquatic ecosystems. This pollution represents a threat for organisms, among them are fish. Consequently, prenatal stress can have important repercussions, and may impact survival and population recruitment. To investigate this point, eggs were collected from zebrafish exposed during 6 months by trophic route to three aromatic fractions from two different origins, pyrolytic (PY) and petrogenic (light (BAL) and heavy (HFO) fractions) sources. Chronic dietary exposure of the parents was performed at environmentally relevant concentrations $(0.3 \times, 1 \times$ and $3 \times ; 1 \times$ represents an environmental concentration measured in French estuary). In order to explore the consequences of parental exposure for the next first generation, toxic responses were studied in both embryos and larvae using a multiscale approach. Toxic effects were assessed by looking at hatching success, developmental abnormalities, photomotor response and heartbeat. The level of PAH metabolites and EROD activity in fish larvae were measured to assess exposure to PAHs. Egg production of parents was significantly reduced compared to the Control; hence little information was available for BAL and HFO offspring. The size of larvae from PY parents was found to increase despite a reduced yolk sac compared to Control larvae. Furthermore, a high level of behavioral stress was observed in larvae originating from parents exposed to three-fold the environmental concentration. The cardiac activity was reduced in a concentration-dependent manner for the PY exposure group. No effect was however observed on biotransformation markers (cyp1a, EROD), nor on the level of DNA damage for all PY, BAL and HFO offspring. The absence of significant differences in metabolite levels may indicate a potential early depuration of transferred compounds or no PAH-transmission. The disruptions observed at the individual level in the next generation could impact on the longer-term, surviving population
\end{abstract}




\section{Highlights}

- We examine the toxicity of organic pollutants in a temporal dynamic (multigenerational study). $\rightarrow$ We examine the consequences of parental trophic exposure to the first offspring generation at different biological level with exposures at environmentally relevant concentrations. We highlight the alteration of two vital functions in fish: the swimming and cardiac performances. Increasing information in the next generation will increase the risk prediction. The multigenerational studies should be widely undertaken to evaluate the potential for exposed-population to maintain in the future.

\section{Abbreviations}

- $\quad$ BAL, Brut Arabian Light;

- EROD, ethoxyresorufin-O-deethylase;

- dpf, days post-fertilization;

- HFO, heavy fuel oil;

- HMW, High Molecular Weight;

- hpf, hours post-fertilization;

- LMW, Low Molecular Weight;

- PAHs, polycyclic aromatic hydrocarbons;

- PY, pyrolytic;

- PMR, PhotoMotor Response;

- RT-PCR, real-time polymerase chain reaction

Keywords : Polycyclic aromatic hydrocarbons, Parental transmission, Fish early-life stages, PhotoMotor Response, Cardiac performance, PAH metabolites, Genotoxicity

\section{Introduction}

In recent decades, increasing industrialization and urbanization has resulted in significant chemical pollution of the aquatic environment (Shen et al., 2013). Among organic pollutants, polycyclic aromatic hydrocarbons (PAHs) are ubiquitous and semi-persistent pollutants in the environment (Laflamme and Hites, 1978). They are lipophilic compounds with two or more fused benzene rings. PAHs can be divided into two groups: the Low-Molecular-Weight (LMW) PAHs 
(PAHs with 2 or 3-benzenic rings) and the High-Molecular-Weight (HMW) PAHs (PAHs presenting more than 3-benzenic rings). PAHs are produced from three pathways: i) pyrolytic processes such as incomplete combustion of organic matter from natural or anthropogenic sources (pyrogenic origin), ii) diagenesis of sedimentary organic matter giving form to fossil fuel (petrogenic origin), iii) natural precursor transformations during early diagenesis processes (diagenetic origin) (Neff, 1979). Although they may be produced naturally, their predominant emission is from anthropogenic sources, including burning of fossil fuel, coal tar, wood, waste incineration, urban runoff, maritime transport discharges and petroleum spills (Neff, 1979). Depending on their origin, PAHs are generally present in complex mixtures that can be characterized by their molecular fingerprint. Indeed, a predominance of HMW compounds associated with the presence of less or non-alkylated PAHs is representative of a pyrolytic mixture. Conversely, a petrogenic mixture is characterized by a majority of LMW PAHs and the presence of methylated compounds (Abrajano et al., 2003; Sakari, 2012).

Due to their physico-chemical properties, most PAHs exhibit hydrophobic and lipophilic properties making them relatively insoluble in water. They have a high capacity to adsorb onto suspended particles or non-polar matrices which respectively favors their accumulation in sediments and in the lipid tissue of organisms. Fish have the ability to biotransform PAHs to more water-soluble metabolites, hence reducing bioaccumulation and transfer efficiency in higher levels of marine food chains (Meador et al., 1995). Nonetheless, benthic invertebrate preys represent important pathways of PAH exposure for demersal fish. Indeed, many invertebrate species such as mollusks can bioaccumulate high PAH concentrations in their fatty tissues (Peterson et al., 2003; Varanasi et al., 1985) due to the lower biotransformation capability (Bustamante et al., 2012; Lee et al., 1972; Palmork and Solbakken, 1981). PAH toxicity in fish can be directly linked to biotransformation by enzymatic systems such as those from cytochrome 
P450, which metabolize PAHs into reactive metabolites (Meador et al., 1995; van der Oost et al., 2003). Some of the metabolites produced are more toxic than the parent compounds, presenting, for example, a high reactivity for the DNA leading to genotoxic effects (Le Dû-Lacoste et al., 2013; Wessel et al., 2012, 2010). However, DNA damage is not necessary linked to activation of enzymatic systems such as ethoxyresorufin-O-deethylase (EROD) activity. A case in point is fluoranthene which is not a potential inducer of EROD activity, while its produced-metabolites exhibit genotoxic effects (Wessel et al. 2012). Furthermore, PAH metabolization can also lead to the production of reactive oxygen species (ROS) which may induce an oxidative stress (Frenzilli et al., 2009).

In aquatic organisms, exposure to PAHs can thus lead to detrimental defects from a developmental, physiological and behavioral point of view (Bihanic et al. 2015; Incardona et al. 2011; 2004; Perrichon et al. 2014). PAHs' impact on reproductive success is particularly studied due to its consequence on population recruitment. Indeed, PAHs can act as endocrine disruptors that interfere and thus lead to adverse reproductive and developmental effects (Cooper and Kavlock 1997; Hawliczek et al. 2012; Monteiro et al. 2000a; Monteiro et al. 2000b). Previous studies showed a reduction of the plasma level of gonad hormones in fish after PAH exposure (Monteiro et al., 2000a; Thomas and Budiantara, 1995). Thomas and Budiantara (1995) highlighted a blockage of sexual maturation, impairments of ovarian recrudescence and induction of oocyte atresia in female Atlantic croaker (Micropogonias undulatus) following exposure to water-soluble fractions of diesel fuel and naphthalene. Similarly, a delay in gonad maturation has been reported in female English sole from sites with high concentrations of PAHs (Casillas et al., 1991; Johnson et al., 2002, 1988) as well as in female Atlantic croaker exposed in the laboratory to benzo[a]pyrene (Thomas, 1990). An exposure to a PAH-contaminated sediment has been shown to reduce spawning in sole (Johnson et al., 2002). PAHs can hence have an effect on the 
parents themselves but also on their offspring. The physiological condition of a female at the time of vitellogenesis was reported as a modulation source for the offspring generation. Prenatal stress (i.e. chemical contamination) could thus affect the optimal development of the early life stage in the future generation (Eriksen et al., 2006; Gagliano and McCormick, 2009; Mccormick, 1999). Uptake of pollutants can occur during ovogenesis and consequently accumulate in the vitellin reserve of the embryos. Relatively few studies reported potential parental transmission of PAHs in offspring generation. Following maternal exposure, the transfer of anthracene in the vitellus of fathead minnows eggs has been shown by Tilghman Hall and Oris (1991). More recently, Pollino et al. (2009) demonstrated a positive correlation between the occurrences of abnormal larvae in offspring with naphthalene-exposed female rainbowfish (Melanotaenia fluviatilis). The transfer of PAHs to the embryos was associated with mortality, hatching delay and growth alterations (Hose et al., 1981; Nye et al., 2007; Tilghman Hall and Oris, 1991).

This study aimed to explore the consequences of parental exposure $\left(\mathrm{F}_{0}\right)$ to PAHs for the next first offspring generation $\left(\mathrm{F}_{1}\right)$ under chronic dietary exposure conditions. Parents were chronically exposed during their whole lifecycle, through diet, to three aromatic fractions of pyrolytic and petrogenic origin, at concentrations which were relevant from an environmental point of view. This study focused on the early life stages of offspring. Multiscale approach was undertaken in order to assess a wide range of fish toxic response, using phenotypic markers (hatching success, developmental abnormalities), behavioral (PhotoMotor Responses), physiological (e.g. heartbeat) and cellular/subcellular markers (DNA damage, apoptosis, oxidative stress). In addition to these effect markers, the degree of exposure to PAHs was evaluated with the level of EROD activity, cypla induction and PAH-metabolites in offspring larvae. 


\section{Materials and Methods}

\subsection{Chemicals}

The Arabian light crude oil (BAL 100) and the heavy fuel oil from the Erika fuel oils (No. 2) used for this study was provided by Cedre (Centre of Documentation, Research and Experimentation on Accidental Water Pollution, France). PAH spiking of food and chemical analysis were performed with dichloromethane solvent from Acros Organics (Thermo Fisher Scientific, Geel, Belgium). The ethyl-4-aminobenzoate (benzocaïne) was purchased from SigmaAldrich (St Quentin Fallavier, France).

\subsection{Preparation of PAH-contaminated food}

Four sizes of food were prepared (i.e. $\leq 125 \mu \mathrm{m}, 125-315 \mu \mathrm{m}, 315-500 \mu \mathrm{m}, \geq 500 \mu \mathrm{m}$ ) from ground commercial food INICIO Plus $0.5 \mathrm{~mm}$ (Biomar, France), in order to adapt the food to the fish morphology throughout the lifecycle (from larvae to adult stages). Each food lot was contaminated by the PAH aromatic fractions as described hereafter. The aromatic fractions were a pyrolytic fraction (PY) extracted from sediments collected in the highly polluted site of Oissel (Seine estuary, France) and two petrogenic fractions extracted from Brut Arabian Light oil (BAL) and heavy Erika fuel oil (HFO). Extraction and quantification of these aromatic fractions based on the 16 priority PAHs listed by US-EPA were performed according to procedures described in Budzinski et al. (1997) and Cachot et al. (2007). PAH and alkylated PAH concentrations were reported in Vignet et al. (2014) and given in Fig. 1 Supplementary data. Dry food was hence spiked with the three PAH fractions according to Vicquelin et al. (2011). Briefly, the amount of 
food required for the experiment was mixed with dichloromethane (Solvent Control) and each tested aromatic extract in a round-bottom glass flask. Then, solvent was completely evaporated with a rotary evaporator (RV10 Basic VWR International) equipped with a heating water bath (HB10 Basic, VWR International) at $45^{\circ} \mathrm{C}$ and until total evaporation. Finally, spiked-food was stored overnight in darkness at room temperature under a fume hood to ensure complete residual solvent elimination. For each aromatic fraction, three concentrations were prepared: $0.3 \mathrm{X}, 1 \mathrm{X}$ and $3 \mathrm{X}$. The nominal environmental concentration $1 \mathrm{X}$ represents the total $\mathrm{PAH}$ concentration measured in mollusks from the Seine estuary corresponding to $5 \mu \mathrm{g}$ PAHs g ${ }^{-1}$ of dry food. PAH and alkylated PAH concentrations measured in contaminated-food were also reported in Vignet et al. (2014) and given in Table 1 Supplementary data.

\subsection{Fish exposure}

\subsubsection{Parental dietary exposure ( $F_{0}$ Generation)}

Wild-type zebrafish (TU strain, Tübingen, Germany) were used for the experiment. The parental dietary exposure was performed during the whole 9 months of the zebrafish lifecycle (larvae, juvenile, and adult). The parental generation was produced from fifty viable eggs per condition, provided by healthy spawning of zebrafish. Then, the eggs were transferred to Petri dishes $(100 \mathrm{~mm})$ filled with $30 \mathrm{~mL}$ of artificial water $\left(0.33 \mathrm{mM} \mathrm{CaCl}_{2}, 0.33 \mathrm{mM} \mathrm{MgSO} 4,5 \mathrm{mM}\right.$ $\mathrm{NaCl}$ and $0.17 \mathrm{mM} \mathrm{KCl}$ ) and incubated at $28 \pm 0.5{ }^{\circ} \mathrm{C}$ until exposure started. Maintenance of the standard conditions of zebrafish was already described in Perrichon et al. (2014). The trophic exposure was then performed from 5 days post-fertilization (dpf) larvae which correspond to the mouth opening stage. The procedure was already described in Vignet et al. (2014). Briefly, larvae 
were transferred in $1 \mathrm{~L}$ tanks in the breeding room and fed ad libitum with aromatic fractionspiked food twice a day. In order to improve growth, larvae were then transferred to 3 and $10 \mathrm{~L}$ tanks from $12 \mathrm{dpf}$ and 3 months post-fertilization (mpf) respectively. From this latter stage, diet rations distributed were set at $2 \%$ of the total biomass. During the 9 months of dietary exposure, a distribution of non-contaminated food with living Artemias sp. nauplii (INVE, Belgium) was given in supplement once a day. Breeding exposure was performed in a constant aeration and flow water systems with daily water renewal set at $40 \%$ in order to maintain optimal water quality. Water and room temperature were kept at $27{ }^{\circ} \mathrm{C}$ with a $14 \mathrm{~h} \mathrm{light} / 10 \mathrm{~h}$ dark photoperiod.

\subsubsection{Offspring production ( $F_{1}$ Generation)}

Eggs were obtained according to two distinct methods. Three spawning boxes $(1 \mathrm{~L}$, AquaSchwarz, Germany) were placed directly into the breeding tank the evening before spawning day. In addition, random pairwise mating was performed. One male and one female were placed together in a spawning box on the evening preceding egg production. With both methods, spawning and fertilization took place within $30 \mathrm{~min}$ after the onset of light in the

morning. They were alternatively used in order to collect eggs twice a week. Fertilized eggs were selected by microscopic exam and viable eggs were distributed in batches of 30 into plastic Petri dishes (100 mm diameter) filled with $30 \mathrm{~mL}$ of artificial water and incubated at $28 \pm 0.5^{\circ} \mathrm{C}$ until analysis.

2.4. Biological analysis

\subsubsection{Hatching and developmental abnormalities}


Sublethal endpoints were recorded as described in Lammer et al. (2009) and Perrichon et al. (2014). Hatching success was monitored daily. Biometric analysis (standard length, whole body and yolk sac surface) and abnormalities were recorded in each Solvent Control and PAH-exposed group. Five categories of abnormalities were scored: 1- Edemas formation (brain, pericardia, yolk sac); 2- Skeletal deformities (scoliosis, lordosis, tail bud deformities); 3- Craniofacial deformities (jaw, development of eyes, head deformities); 4- Cardiac deformities (anemia, hemorrhage, atrium/ventricle size, blood circulation heart position); 5- Yolk sac malabsorption. Moreover, a scoring matrix (score of 0-3) was applied following occurrence and severity of these abnormalities: (0) healthy larvae, (1) one abnormality or mildly-affected larvae, (2) two abnormalities or moderately affected larvae, (3) three abnormalities or more or severely affected larvae. Results were expressed in percentage.

\subsubsection{Impact on behavioral: swimming activity}

PhotoMotor Response on 120 hpf larvae were monitored, following the procedure described by Péan et al. (2013) with modifications by Perrichon et al. (2014). Briefly, the locomotor activity of larvae was recorded during a light/dark change challenge in a temperaturecontrolled box $\left(28 \pm 0.5^{\circ} \mathrm{C}\right)$. Recording included three periods of $5 \mathrm{~min}$ : 5 min Light On (1), 5 min Dark (D) and 5 min Light On (2). Video analyses were performed with Ethovision XT 8.5 software (Noldus, The Netherlands). The behavioral performances of larvae were assessed by measuring the swimming distance $(\mathrm{cm})$ during these three periods. This distance was calculated considering the center point of the larvae between two consecutive $\mathrm{X}-\mathrm{Y}$ coordinates summed over a 5-min periods. 


\subsubsection{Effects on cardiac activity}

Cardiac activity was recorded at $28 \pm 0.5^{\circ} \mathrm{C}$ on $120 \mathrm{hpf}$ larvae. Larvae were introduced in 1 $\mathrm{mm}$ wide lines molded in agarose (2\%), immobilized with $3 \%$ methylcellulose and positioned in a lateral view. An acclimation of 2 hours, in a temperature-controlled environment $\left(28 \pm 0.5^{\circ} \mathrm{C}\right)$, was performed before analysis in order to stabilize heartbeat. The heart area of each fish was recorded under an inverted microscope (Olympus SZX9, 40x) coupled to a camera (DMK 31AU03, The Imaging Sources, Germany) and to IC Capture 2.2 software (The Imaging Sources, Germany). Larvae were placed under the microscope for two minutes before recording their heartbeat in order to acclimatize them to the light microscope. For each larvae, three successive videos of 30 seconds were acquired. Video analysis was performed in three successive processing steps: i) A video conversion was made in images stack to greyscale using VirtualDub 1.9.11 software (http://www.virtualdub.org/). A total of 450 images were extracted per 30 seconds of video; ii) An images analysis was performed using ImageJ software (Schneider et al., 2012), focusing on two ROIs (Regions Of Interest) manually delimited and corresponding to the atrium and ventricle, both cardiac chambers. The integrated analysis of grey intensity was performed for each image in both ROI previously converted in order to calculate the alternate circulation between both chambers; and iii) Calculation of cardiac frequency for both chambers from a Single Spectrum (Fourier) analysis was made on integrated data of grey intensity with Statistica 9.0 software (StatSoft, USA). Cardiac frequencies were then corrected to obtain data expressed in beat. $\min ^{-1}$.

\subsubsection{EROD activity}


EROD activity as an indicator of phase I biotransformation activity was determined following the procedure described by Perrichon et al. (2014). To summarize, $96 \mathrm{hpf}$ larvae were incubated in 7-ethoxyresorufin for 5 hours. Levels of produced resorufin into gastrointestinal cavity were observed by fluorescence microscopy (excitation/emission, $560 \mathrm{~nm} / 580 \mathrm{~nm}$ ) and quantified by imaging analysis software ImageJ (Schneider et al., 2012) coupled with HeatMap Histogram plugin (Péan S., http://www.samuelpean.com/heatmap-histogram/). Fluorescence results were expressed in integrated density of pixels (arbitrary unit).

\subsubsection{DNA integrity of the offspring}

DNA strand break measurements by the alkaline comet assay were performed on $24 \mathrm{hpf}$ embryos. Pools of five dechorionated embryos for four samples per concentration were digested with $1 \mathrm{mg} \cdot \mathrm{mL}^{-1}$ of phosphate-buffered saline $1 \mathrm{X} /$ collagenase IV from Clostridium histolyticum (PBS 1X, $137 \mathrm{mM} \mathrm{NaCl} \cdot \mathrm{KCl} 2.7 \mathrm{mM} \cdot \mathrm{Na}_{2} \mathrm{HPO}_{4} 10 \mathrm{mM} \cdot \mathrm{KH}_{2} \mathrm{PO}_{4} 1.8 \mathrm{mM}$, pH 7.4, SigmaAldrich, Germany) solution during 45 minutes at room temperature. Cell suspension was filtered through $48 \mu \mathrm{m}$ gauze into a $1.5 \mathrm{~mL}$ reaction tube in order to separate individual cells from tissue debris. Following a centrifugation for 10 minutes at $2300 \mathrm{rpm}$ at room temperature, the cells pellet was resuspended with $30 \mu \mathrm{l}$ of PBS. The viability of the dissociated embryo cells was evaluated by a Trypan blue exclusion test. Then, the comet assay was performed as described by Akcha et al. (2003). Two slides were prepared per sample. DNA was stained with $70 \mu \mathrm{L}$ of GelRed ${ }^{\mathrm{TM}}$ solution $(1 / 10000)$ for one hour at $4{ }^{\circ} \mathrm{C}$ in the dark. Slides were analyzed using a fluorescence microscope (Olympus BX60, 400x) coupled to a Luca-S EMCCD camera (Andor ${ }^{\mathrm{TM}}$ technology, Northern Ireland) and imaging analysis software (Komet 6.0, Andor ${ }^{\mathrm{TM}}$ Technology, 
Northern Ireland). Genotoxic assessment was assessed by measuring the DNA percentage in the comet tail (50 cells per slide).

\subsubsection{Gene expressions}

Larvae were sampled at $96 \mathrm{hpf}$ and stored in RNA Later (Sigma-Aldrich) at $-20{ }^{\circ} \mathrm{C}$ until used. Total RNA were extracted on 20 pooled larvae using Trizol® Reagent (Invitrogen, Carlsbad, CA, USA) following the manufacturer's instructions with chloroform/ethanol purifications. Total RNA concentration extracted was quantified by spectrophotometry at 260 nm. Furthermore, purity of RNAs was verified by measuring the A260/A230 nm and A260/A280 $\mathrm{nm}$ ratios and by electrophoresis on a $1.8 \%$ agarose gel with ethidium bromide staining. To avoid the possibility of genomic DNA contamination, the RNA sample was digested by RNase-free DNase I (Promega Madison, USA) and then purified.

Then, a reverse transcription of RNA was performed. First-strand cDNA was synthetized from total $1 \mu \mathrm{g}$ RNA using a reaction mix including $500 \mathrm{ng}$ of oligo $\left(\mathrm{d}_{\mathrm{T}}\right) 15,250 \mathrm{ng}$ of random hexamer primers (Promega, Madison, USA), $10 \mathrm{mM}$ of deoxyribonucleotide triphosphates (dNTPs) solutions to a final volume of $10 \mu$ l. The reaction was initiated using M-MLV Reverse Transcriptase 5X (Promega, Madison, USA) following manufacturer's instructions. Reaction was incubated for $1 \mathrm{~h}$ at $42{ }^{\circ} \mathrm{C}$ in an Eppendorf Mastercycler and inactivated by heating for $15 \mathrm{~min}$ at $70^{\circ} \mathrm{C}$. The cDNA mixture was stored at $-20^{\circ} \mathrm{C}$ until a real-time PCR analysis.

PCR primers were designed with Primer3 software (Rozen and Skaletsky, http://bioinfo.ut.ee/primer3-0.4.0/). The accession numbers of the 11 genes used in our study and the corresponding primers are reported in Table 1. Real-time PCR reactions were performed in sterile 96-well PCR plates with StepOnePlus ${ }^{\mathrm{TM}}$ instrument (Applied Biosystems ${ }^{\circledR}$, Life 
Technologies USA) following the manufacturer's instructions. Quantification procedure was based on fluorescence of reaction mixture which related to double-stranded DNA. This reaction mixture included Fast SYBR ${ }^{\circledR}$ Green Master Mix 5X (Applied Biosystems ${ }^{\circledR}$, USA), $2.4 \mu \mathrm{L}$ of primers at $600 \mathrm{nM}$ (Eurofins MWG Operon, Germany), $5.6 \mu \mathrm{L}$ of Milli-Q water and $2 \mu \mathrm{L}$ of cDNA. Thermal cycling conditions were: enzymatic activation during $10 \mathrm{~min}$ at $95{ }^{\circ} \mathrm{C}$, followed by 40 cycles including denaturation $\left(95^{\circ} \mathrm{C}, 15 \mathrm{~s}\right)$, annealing $\left(60^{\circ} \mathrm{C}, 40 \mathrm{~s}\right)$ and synthesis $\left(72^{\circ} \mathrm{C}\right.$, $30 \mathrm{~s})$. Gene expression levels were quantified from the threshold cycle (CT) number and normalized to three housekeeping genes: eefl, Bactin, gapdh.

\subsubsection{PAH-metabolites analysis in larvae}

Larvae were sampled at $120 \mathrm{hpf}$ and stored at $-80{ }^{\circ} \mathrm{C}$ until used. Metabolites were extracted on 50 pooled larvae and three replicates per concentration. Larvae were manually homogenized in 3-4 $\mathrm{mL}$ of sodium acetate buffer $(\mathrm{pH} 5.0)$. An enzymatic deconjugation was performed for 16 hours at $37^{\circ} \mathrm{C}$ after addition to $20 \mu \mathrm{L}$ of beta-glucuronidase enzyme from Helix pomatia-2 ( $\geq 100000$ units.mL ${ }^{-1}$, Sigma-Aldrich, Germany) using a method adapted by Mazéas and Budzinski (2005). Prior to PAH-metabolites extraction, internal standards solution was added to samples. Metabolites were extracted by a Solid-Phase Extraction (SPE) procedure using octadecyl cartridge (500 mg, 3 cc, Bakerbond $\mathrm{C}_{18}$-SPE) and eluted in 100\% methanol solvent. After re-concentration of organic extracts with gas nitrogen, samples were purified by SPE using amino-column (500 mg, 3 cc, Supelco $\mathrm{NH}_{2}$-SPE) and eluted with dicholoromethane/methanol solution $(80 / 20, \mathrm{v} / \mathrm{v})$. After another re-concentration step with gas nitrogen, PAH-metabolites (hydroxy-PAH, OH-PAH) extracts were analyzed by Liquid Chromatography coupled to tandem 
Mass Spectrometry (LC/MS/MS) analysis as described in Le Dû-Lacoste et al. (2013). PAH concentrations are reported as ng OH-PAH.g ${ }^{-1}$ larvae.

\subsection{Statistical analysis}

Sampling procedure of chemical and biological analyses was reported in Table 2. Statistical analyses were performed using Statistica 9.0 software (StatSoft, USA). Results are expressed as means \pm standard error of means (SEM) corresponding to experimental groups. A logarithm transformation was performed on comet assay data for normalization (Zar, 2010). The assumption of normality (Shapiro-Wilk tests) and homoscedasticity of variance (Levene tests) were verified. Biological data were analyzed by a one-way analysis of variance (ANOVA) in order to assess significant effects between tested concentrations for each treatment (PY, BAL, HFO). When only two concentrations were tested, a student $t$ test was performed. For PAHmetabolites analyses, normality and homoscedasticity were not validated; therefore a nonparametric Kruskal-Wallis test and Mann-Whitney test were performed.

Behavioral data for PY treatment were analyzed using a one-way repeated measure ANOVA (R-ANOVA) with exposure concentrations as a dependent factor and light (Light On(1), Light Off and Light On(2)) as a within factor. A post-hoc Newman Keuls test was performed each time a difference was found to be significant. For behavioral data of BAL and HFO treatments, normality and homoscedasticity were not validated; therefore non-parametric Mann-Whitney tests were used. In order to test significant differences between three challenge periods, Kruskal-Wallis tests were conducted with multiple pairwise comparisons. 
Gene expressions were analyzed with a Relative Expression Software Tool REST-2009C (Qiagen, http://www.REST.de.com). The gene expression level was given in a relative expression ratio compared to the control condition.

The significance of the results was ascertained at $\alpha=0.05$.

\section{Results and Discussion}

Following 6 months of parents' exposure to the three aromatic fractions (PY, BAL and HFO), PAHs-metabolites were detected in whole larvae of the $\mathrm{F}_{0}$ generation showing that a parental contamination had occurred (Vignet et al. 2014). The mean number of spawning events and batch fecundity obtained from these exposed parents were also reported by these authors (Vignet, 2014). Parents' reproduction of $3 \mathrm{X}$ concentrations for the three treatments was severely impaired. Similar results were recorded in $1 \mathrm{X}$ concentrations for fish exposed to BAL and HFO aromatic fractions. These complex mixtures have direct consequences on egg production with no eggs or few eggs obtained for these concentrations. Consequently, analyses of the offspring were not possible in the case of any egg production. For samples with an insufficient number of eggs, statistical analyses have not been performed and thus the results were given on an indicative basis.

3.1. Morphological impairments in offspring larvae ( $\mathrm{F}_{1}$ generation)

No hatching delay was observed in offspring larvae whatever the nature and the concentration of the PAH extract tested. Hatching rates in offspring larvae from PY and BAL exposed parents were not significantly different whatever the tested concentrations (Fig. 1A, 1B) 
$(\mathrm{P}>0.05)$. Statistical analyses revealed a decrease in the hatching rate $(2.0$-fold $)$ in larvae from HFO-0.3X parents compared to the Solvent Control group $(\mathrm{P}<0.001)$ at the first hatching day (48 hpf) (Fig. 1C). However, no significant difference was recorded for the following days, with hatching rates averaging $100 \%$. Regarding these latter results, it should be noted that this decrease observed at $48 \mathrm{hpf}$, probably did not lead to the PAH parental transmission but only to the hatching process unsynchronization in zebrafish (Kimmel et al., 1995). Only one spawning was obtained from HFO-1X exposed parents, consequently statistical analysis was not possible. Data are thus represented on an indicative basis. Therefore, our results did not show any alteration of hatching success in the first generation offspring from parents exposed to three PAH complex mixtures. In spite of the fact that relatively few studies reported results about PAHs transmission to offspring generation, Hose et al. (1981) have however demonstrated a reduction of hatching success in offspring eggs after $\mathrm{BaP}$ injection in the gonads of sexually mature flatfish. Similarly, Hall and Oris (1991) have reported that maternally transferred anthracene reduced hatching success in the offspring eggs of fathead minnows (Pimephales promelas). In addition, Nagler and Cyr (1997) have proved a significant decline in the number of hatched larvae because of sperm quality alteration in male American plaice (Hippoglossoides platessoides) exposed to contaminated sediment.

Biometric measurements in offspring larvae originating from PY, BAL and HFO fractionsexposed parents are presented in Table 3. Offspring larvae from PY-0.3X treatment were slightly longer than Solvent Control and PY-1X larvae $(\mathrm{P}<0.001$ both). Yolk sac surface and ratio yolk sac/whole body surfaces of larvae from $0.3 \mathrm{X}$ and $1 \mathrm{X}$ concentrations were slightly reduced compared to Solvent Control larvae $(\mathrm{P}<0.001$ both). Larvae originating from HFO-0.3X parents were slightly longer than Solvent Control larvae $(\mathrm{P}<0.001)$. No significant difference in yolk sac surface, in ratio yolk sac/whole body surfaces were detected in these offspring larvae $(\mathrm{P}>0.05)$. In 
addition, Table 3 gives a summary of abnormal larvae proportions and details of abnormalities and their associated severity in larvae. No significant morphological abnormalities were recorded between tested concentrations compared to Solvent Control, whatever the parental treatment ( $\mathrm{P}>0.05$ ). Abnormal individuals (and mainly mild-affected) ranged from 3.34 to $11.1 \%$ for PY offspring larvae, from 21.9 to $25.9 \%$ for BAL offspring larvae and from 18.0 to $19.8 \%$ for HFO offspring larvae. Taken together, these results showed that PAHs transmitted from the parents induced some biometric impairment. However, the toxic action of PAHs transmitted following these treatments will be not so severe as to induce edemas, skeletal, craniofacial deformations in offspring larvae. These results are in accordance with those of Nye et al. (2007) who demonstrated that offspring larvae from contaminant-exposed mothers were longer with smaller yolk sacs than larvae produced by unexposed mothers. From those results, two hypothesis were proposed to explain these differences in size : i) the spawning event from contaminant-exposed mothers took place earlier or ii) a faster development in offspring embryos which will consume more yolk reserves compared to reference embryos. In the present study, development of offspring embryos was assessed during $96 \mathrm{hpf}$, from 30 min after spawning and no growth delay were recorded whatever the parental treatment considered. In addition, a greater number of hatched larvae would be then observed earlier. Therefore, the first hypothesis is unlikely. Thus, a greater consumption of nutritional reserves in offspring larvae from exposed parents is possible to offset potential physiological failure before hatching, leading to faster development, which would explain longer larvae at $96 \mathrm{hpf}$. Survival time in starved offspring larvae during $15 \mathrm{dpf}$ was not assessed in the present study, but this parameter will be determinant to assess this potential consumption of reserves and therefore the resistance to starvation. A reduced ability by larvae to resist starvation could lead to a decline in the fish population. 
3.2. Behavioral disruptions in offspring larvae ( $F_{1}$ generation)

Behavioral responses were analyzed in order to assess the potential developmental neurotoxic effects of parental transmission. These responses are currently used to assess the toxicity of various compounds through the analysis of swimming capacity, stress-regulating systems and motor responses (perception and reaction) to stimuli (Champagne et al., 2010; Drapeau et al., 2002; de Esch et al., 2012; Linney et al., 2004). Figure 2 presents the measurements of distance moved per 5-min intervals in offspring larvae from PY, BAL and HFO-exposed parents following a light/dark challenge. Whatever the tested-aromatic fraction, response patterns of offspring larvae were similar, dissociating three swimming activity phases as reported in the literature: i) basal swimming activity phase (Light On(1)), ii) challenge phase (Light Off) leading to an increasing swimming activity and iii) the recovery phase (Light On(2)) when the light is turned on again, where swimming activity was comparable to that observed in the basal phase (Kokel et al., 2010; MacPhail et al., 2009; Padilla et al., 2011). The swimming activity of larvae from PY-3X parents was significantly higher than the other concentrations during both light periods $(\mathrm{P}<0.05)$ (Fig. $2 \mathrm{~A})$. Our results clearly demonstrated hyperactivity for 3X offspring larvae from PY-exposed parents during all behavioral challenges. The ability of these larvae to swim a greater distance could be due to the greater length and/or a possible neurotoxic stimulation of transferred-pyrolytic mixture. The significant lack of morphological data for this condition did not support the first hypothesis. Furthermore, results obtained in PY0.3X offspring larvae did not reflect these findings. While these larvae had a high swimming activity, these results primarily demonstrate a high level of basic stress, a lower tolerance during the stress period and lower stress recovery. Regarding offspring larvae from BAL-0.3X parents (Fig. 2B), while no significant difference was observed in the basal swimming activity phase, 
their PMR pattern tended to be similar to the PMR pattern in PY-3X larvae $(\mathrm{P}>0.05)$. Indeed, these larvae showed a significant increase in the distance moved during the recovery phase (Light On(2), $\mathrm{P}=0.01$ ). Regarding HFO treatment (Fig. 2C), PMR of $0.3 \mathrm{X}$ offspring larvae was significantly reduced during the all light/dark challenge compared to Solvent Control larvae (Light On(1): $\mathrm{P}<0.001$, Light Off: $\mathrm{P}=0.002$, Light $\mathrm{On}(2)$ : $\mathrm{P}<0.001$ ). Their behavioral responses were in total opposition with those of PY and BAL larvae, where $0.3 \mathrm{X}$ offspring larvae displayed a significant early lethargic activity whatever the swimming activity phase. No data were available for $1 \mathrm{X}$ and $3 \mathrm{X}$ concentrations in either BAL or HFO offspring larvae. According to current understandings, this is the first study concerning behavioral assessment of complex PAHs mixtures in the offspring of contaminated fish and relatively few studies have dealt with the impact of organic pollutant on the fish PMR. Therefore, we cannot directly compare effects with those reported in the literature. However, using a similar approach, Péan et al. (2013) have reported stimulation of this PMR in offspring zebrafish larvae originating from fish contaminated with polychlorinated biphenyls. Their results proved that a potential transmission of organic pollutants may alter the neurotoxic development of offspring. Recently, our previous studies have reported a reduction of basal swimming activity and response to light stress in ELS of zebrafish and an increase in Japanese medaka following sediment contact exposures with two unique PAH, fluoranthene (3-benzenic rings $\mathrm{PAH}$ ) and benzo[a]pyrene (5-benzenic rings $\mathrm{PAH}$ ) respectively (Perrichon et al. 2014). A reduction in the swimming activity behavioral pattern was also recorded in Japanese medaka after exposure to benzo[a]anthracene (4-benzenic rings) (Bihanic et al. 2015). The present study demonstrated a parental influence in the neurotoxic behavior of their offspring. These modifications in swimming activity could be critical for vital functions like their visual acuity, their hunting behavior or their escape response to predation or for the spawning migrations, which could be significantly reduced (Gonçalves et al., 2008). However, it is 
unknown whether any of the above observations translate to physiological defects and to fitness in surviving fish over the longer-term.

\subsection{Physiological disruptions in offspring larvae ( $\mathrm{F}_{1}$ generation $)$}

Behavior impairments observed previously may be caused by physiological alterations. Therefore, cardiac activity in 120 hpf offspring larvae from parents exposed to three aromatic fractions was measured and represented in Fig. 3. While no morphological abnormalities (edemas, anemia, hemorrhages) were observed, a decrease in the cardiac activity was observed to be concentration dependent in larvae originating from PY parents, with respectively 159, 165 and 148 heartbeats. $\mathrm{min}^{-1}$ for $0.3 \mathrm{X}, 1 \mathrm{X}$ and $3 \mathrm{X}$ concentrations $(\mathrm{P}=0.01, \mathrm{P}=0.03$ and $\mathrm{P}<0.001)$. In contrast, heartbeat was not significantly different compared to the Solvent Control respectively in offspring larvae from BAL and HFO parents. No data available for HFO-1X and BAL/HFO-3X. Cardiac frequencies recorded in Solvent Control larvae were consistent with those reported in the literature at this development stage (Barrionuevo and Burggren, 2013).

Numerous studies have documented cardiac defects following PAH exposure. The toxic action of unique predominant PAHs (from 3 to 5-benzenic rings PAHs) in the cardiovascular system of zebrafish mainly leads to pericardial edema, blockage of blood circulation and bradycardia (Incardona et al., 2011, 2009, 2004). Reduction in heart rate has also been reported in herring embryos and zebrafish embryos after respectively water-soluble fraction exposure of Alaska crude oil (Middaugh et al., 1998, 1996) and after sediment eluates/extracts exposure (Strmac et al., 2002). Recently, Milinkovitch et al. (2013; 2012) recorded cardiac impairments in terms of contraction velocity and not contraction force following a water-soluble fraction exposure of crude oil in golden grey mullets (Liza aurata). Similarly, the excitation-contraction 
coupling in cardiomyocytes of juvenile bluefin and yellowfin tunas was disrupted after exposure to Deepwater Horizon crude oil (Brette et al. 2014). For similar oil, Incardona et al. (2014) have shown serious defects in heart development with circulatory disruption and irregular atrial arrhythmia in three pelagic fish: bluefin tuna, yellowfin tuna and an amberjack. These physiological responses (bradycardia) observed in PY offspring larvae could indicate metabolic disruptions (e.g. respiratory distress) and thus alter fish fitness and survival (Claireaux et al., 2005). Our results are in agreement with those obtained by Lucas et al. (2014) who assessed aerobic metabolic performance in offspring fish from PY-3X parents. These authors have recorded a decrease of active metabolic rate in 2 month-old fish originating from exposed parents, thus reflecting earlier cardio-respiratory impairments. Taken together, the present results are in agreement with those of Davoodi and Claireaux (2007) who demonstrated that cardiac defects observed in sole (Solea solea) exposed to petroleum hydrocarbons induced a reduced AMR. However, we cannot attribute the changes in swimming activity to the heart disruption.

A lack of data in other biological parameters excluded any specific conclusions as to the potential PAH transmission and toxicity effects in offspring for BAL and HFO treatments.

\subsection{Genotoxic effects in offspring $\left(\mathrm{F}_{1}\right.$ generation $)$}

Genotoxic effects on offspring embryos and larvae following the PAH exposure of parents were investigated through the analysis of detoxification, oxidative processes and DNA damage. Whatever the tested fractions (PY, BAL or HFO), no significant differences in levels of EROD activity were observed in $96 \mathrm{hpf}$ offspring larvae compared to respective Solvent Control $(\mathrm{P}>0.05)$ (Fig. 4). Similarly, comet assay did not reveal any significant differences $(\mathrm{P}>0.05)$ in 
the levels of DNA strand breaks measured earlier in $24 \mathrm{hpf}$ offspring embryos from contaminated parents, whatever the tested-concentrations for PY, BAL and HFO fractions (Fig. 5). Unfortunately, no data were available for all $3 \mathrm{X}$ concentrations and HFO-1X. Furthermore, relative expressions of target genes compared to respective Solvent Control are presented in Table 4. Data obtained in larvae offspring were normalized to three housekeeping genes: eefl, Bactin, gapdh. No data were available for BAL-3X and HFO-3X. Regarding offspring larvae from parents exposed to PY aromatic fraction, no significant expression change was revealed between all concentrations for genes involved in the detoxification (cypla, ahr2), antioxidant defense $(\operatorname{gpx} 4 a, c a t, \operatorname{sod}(\mathrm{Cu} / \mathrm{Zn}), \operatorname{sod}(\mathrm{Mn}))$ and the apoptosis processes $(p 53$, bax $)$. Similarly, no significant differences in terms of detoxification (cypla, ahr2) processes were found at $0.3 \mathrm{X}$ and $1 \mathrm{X}$ concentrations for BAL and HFO compared to their respective Solvent Control $(\mathrm{P}>0.05)$. With regards to $\operatorname{Sod}(\mathrm{Mn})$, expression levels were 1.30-fold up-regulated in larvae offspring from BAL-1X parents $(\mathrm{P}=0.006)$. Expression of gene encoding for gpx4 was 0.59 -fold repressed in offspring larvae from HFO-1X parents $(\mathrm{P}=0.018)$. The expression levels of others genes encoding for antioxidant defenses were not significantly different compared to Solvent Control. However, apoptosis processes appeared slightly impacted in offspring larvae from BAL-0.3X parents, with expression levels 1.47-fold and 1.30-fold higher than Solvent Control for $p 53$ and bax respectively ( $\mathrm{P}=0.03$ for both conditions). In contrast, no significant change in either genes was observed in $1 \mathrm{X}$ offspring larvae. For offspring larvae from HFO-1X parents, the $p 53$ level was significantly up-regulated $(\mathrm{P}=0.03)$.

Taken together, these results showed no evidence of repairable or unrepairable DNA damage or potential activation of detoxification processes ( $a h r 2$, cypla, EROD) despite parental exposure to PAHs that are potential inducers of these activities. These results are in agreement with those directly found in the parental generation of our offspring larvae (Larcher et al. 2014). 
Indeed, these authors have recorded a high incidence of tumors related to a refractory detoxification bioactivation or DNA damage (DNA strand breaks and micronuclei) via dietary exposure, whatever the aromatic fraction considered. In parallel, a kinetic of cyp la expression related to the larval feeding condition was performed and had demonstrated that following a 24hour starvation period, an early activation of cypla occurred after a new feeding event with contaminated food, but rapidly returned to background level. This might explain the absence of genotoxic effects in parental generation and consequently in the first generation of offspring in case of genetically-based response transmission.

Furthermore, fish have a high ability to biotransform PAHs, and are therefore able to eliminate a significant part of these compounds (Aas et al. 2000; Budzinski et al. 2004; Jonsson et al. 2004). PAH-metabolites (OH-PAH) concentrations were then measured in offspring larvae in order to identify parental contamination transmission. The hydroxynaphtalene $(\mathrm{OH}-\mathrm{N})$ and dihydroxybiphenyl (2-OH-Bi) were predominant metabolites produced in offspring larvae from PY, BAL and HFO fractions (Table 5). A relatively low level of 1-hydroxypyrene (1-OH-Pyr) metabolite was also present in larvae. However, the amount of metabolites was not statistically different between tested concentrations, from each origin fractions ( $\mathrm{P}>0.05)$, which could explain the absence of a genotoxic effect. Furthermore, among these PAH-metabolites measured, none are potentially genotoxic (Le Dû-Lacoste et al., 2013).

Regarding, toxicity associated with the three aromatic fractions, the HFO fraction appeared to have greater toxicity with an induced-mortality, growth and reproductive disruptions, which lead to a significant reduction in egg production, followed by BAL and PY fractions (Vignet 2014). Although HFO and BAL fractions were the most reprotoxic, only a narcotic effect appeared in offspring larvae of HFO-0.3X, which was not closely linked to cardiac activity or 
genotoxic impairments. Furthermore, the slight induction of p53 and bax involved in proapoptotic processes for both of these fractions, lead us to believe that processes of cellular reparation were induced to offset the potential detrimental effects, which might also explain the absence of genotoxic effects. Finally, regarding biological responses, no conclusion can be drawn about contamination transmission or a stress transfer via neurotransmitters to the eggs.

\section{Conclusion}

Whereas early reproduction alteration was shown to lead to a significant reduction of produced eggs under environmentally relevant conditions, our study also demonstrated that longterm and chronic dietary exposures of zebrafish to PAH mixtures (from their first meal) led to impairments in their first offspring generation. Using a multiscale approach of toxicity endpoints, the present study reported some disruptions on the individual level. Larval offspring from parents exposed to PY fraction showed a higher degree of adverse effects than offspring from BAL and HFO parents. Indeed, mild morphometrical changes were recorded and bradycardias were significantly induced in larvae from PY parents. Behavioral disruptions were shown at the highest exposure concentration (3X), with basal hyperactive swimming and low reaction to second stress. From acquired data, behavioral changes (lethargy and hyperactivity post-stress) were also demonstrated in offspring from BAL and HFO parents. It appears surprising that these effects were not related to bioactivation of processes involved in detoxification, oxidative stress or DNA damage which might be expected to explain a major part of these disruptions. A supplementary focus on the underlying mechanisms of lipid peroxidation should be performed in order to identify potential disruptions in the energetic mechanisms. Similarly, metabolic hormones (e.g. cortisol) should be analyzed in order to validate these biological responses, which 
are potentially released into the nutritive yolk sac during ontogenesis closely associated with the female condition. Furthermore, the lack of data and experiments in the literature compels us to be cautious in our conclusions. Multigenerational studies have proven to be an integrated approach for the toxicity assessment of chemicals and strengthen the predictive effects. These ecotoxicological studies should be widely undertaken to evaluate the potential for the exposed population to maintain its numbers in the future.

\section{Acknowledgments}

Financial support for the $\mathrm{PhD}$ grant was received by $\mathrm{PP}$ from both the Conseil Général de Charente Maritime and the Institut Français de Recherche pour l'Exploitation de la Mer (Ifremer). This work was supported by the French Agence Nationale pour la Recherche (ANR), "Contaminant, Ecosystème et Santé" program, in the framework of the ConPhyPoP (2009-002) research project and CPER A2E. This project is co-financed by the European Union with the European fund of regional development. The authors would like to thank the CEDRE for providing the crude oils necessary to the extraction of aromatic fractions. J. Lucas, L. Lyphout and C. Vignet are thanked for their help with zebrafish breeding maintenance, L. Joassard for performing the qPCR analyses and D. Leguay for technical support on zebrafish behavioral assays. This study was conducted with the approval of the Animal Care Committee of France under the official license of Marie-Laure Bégout (17-010).

\section{References}


Aas E, Baussant T, Balk L, Liewenborg B, Andersen OK. PAH metabolites in bile, cytochrome P4501A and DNA adducts as environmental risk parameters for chronic oil exposure: a laboratory experiment with Atlantic cod. Aquat Toxicol 2000;51:241-258.

Abrajano TA, Yan B, O’Malley V. High molecular weight petrogenic and pyrogenic hydrocarbons in aquatic environments. Treatise on Geochem 2003;9:475-509.

Akcha F, Vincent Hubert F, Pfhol-Leszkowicz A. Potential value of the comet assay and DNA adduct measurement in dab (Limanda limanda) for assessment of in situ exposure to genotoxic compounds. Mutat Res 2003;534:21-32.

Barrionuevo WR, Burggren WW. O2 consumption and heart rate in developing zebrafish (Danio rerio): influence of temperature and ambient O2. Am J Physiol Regul Integr Comp Physiol 2013;276:505-513.

Brette F, Machado B, Cros C, Incardona JP, Scholz NL, Block BA. Crude oil impairs cardiac excitation-contraction coupling in fish. Science 2014;343:772-776.

Budzinski H, Jones I, Bellocq J, Picrard C, Garrigues P. Evaluation of sediment contamination by polycyclic aromatic hydrocarbons in the Gironde estuary. Mar Chem 1997;58:85-97.

Budzinski H, Mazéas O, Tronczynski J, Désaunay Y, Bocquené G, Claireaux G. Link between exposure of fish (Solea solea) to PAHs and metabolites : Application to the "Erika " oil spill. Aquat Living Resour 2004;17:329-334.

Bustamante P, Luna-Acosta A, Clemens S, Cassi R, Thomas-Guyon H, Warnau M. Bioaccumulation and metabolisation of (14)C-pyrene by the Pacific oyster Crassostrea gigas exposed via seawater. Chemosphere 2012;87:938-944.

Cachot J, Law M, Pottier D, Peluhet L, Norris M, Budzinski H, Winn R. Characterization of toxic effects of sediment-associated organic pollutants using the lambda transgenic medaka. Environ Sci Technol 2007;41:7830-7836. 
Casillas E, Misitano D, Johnson LL, Rhodes LD, Collier TK, Stein JE, Mccain BB, Varanasi U. Inducibility of spawning and reproductive success of female english sole (Parophrys vetulus) from urban and nonurban areas of puget sound, Washington. Mar Environ Res 1991;31:99-122.

Champagne DL, Hoefnagels CCM, de Kloet RE, Richardson MK. Translating rodent behavioral repertoire to zebrafish (Danio rerio): relevance for stress research. Behav Brain Res $2010 ; 214: 332-342$.

Claireaux G, McKenzie DJ, Genge a G, Chatelier A, Aubin J, Farrell AP. Linking swimming performance, cardiac pumping ability and cardiac anatomy in rainbow trout. J Exp Biol 2005;208:1775-1784.

Cooper RL, Kavlock RJ. Endocrine disruptors and reproductive development: a weight-ofevidence overview. J Endocrinol 1997;152:159-166.

Davoodi F, Claireaux G. Effects of exposure to petroleum hydrocarbons upon the metabolism of the common sole Solea solea. Mar Pollut Bull 2007;54:928-934.

Drapeau P, Saint-Amant L, Buss RR, Chong M, McDearmid JR, Brustein E. Development of the locomotor network in zebrafish. Prog Neurobiol 2002;68:85-111.

Le Dû-Lacoste M, Akcha F, Dévier M-H, Morin B, Burgeot T, Budzinski H. Comparative study of different exposure routes on the biotransformation and genotoxicity of PAHs in the flatfish species, Scophthalmus maximus. Environ Sci Pollut Res 2013;20:690-707.

Eriksen MS, Bakken M, Espmark a., Braastad BO, Salte R. Prespawning stress in farmed Atlantic salmon Salmo salar: maternal cortisol exposure and hyperthermia during embryonic development affect offspring survival, growth and incidence of malformations. $\mathrm{J}$ Fish Biol 2006;69:114-129. 
De Esch C, van der Linde H, Slieker R, Willemsen R, Wolterbeek A, Woutersen R, De Groot D. Locomotor activity assay in zebrafish larvae: influence of age, strain and ethanol. Neurotoxicol Teratol 2012;34:425-433.

Frenzilli G, Nigro M, Lyons BP. The Comet assay for the evaluation of genotoxic impact in aquatic environments. Mutat Res 2009;681:80-92.

Gagliano M, McCormick MI. Hormonally mediated maternal effects shape offspring survival potential in stressful environments. Oecologia 2009;160:657-665.

Gonçalves R, Scholze M, Ferreira AM, Martins M, Correia AD. The joint effect of polycyclic aromatic hydrocarbons on fish behavior. Environ Res 2008;108:205-213.

Hawliczek A, Nota B, Cenijn P, Kamstra J, Pieterse B, Winter R, Winkens K, Hollert H, Segner H, Legler J. Developmental toxicity and endocrine disrupting potency of 4-azapyrene, benzo[b]fluorene and retene in the zebrafish Danio rerio. Reprod Toxicol 2012;33:213223.

Hose JE, Hannah JB, Landolt ML, Miller BS, Felton SP, Iwaoka WT. Uptake of benzo[a]pyrene by gonadal tissue of flatfish (family pleuronectidae) and its effects on subsequent egg development. J Toxicol Environ Health 1981;7:991-1000.

Incardona JP, Collier TK, Scholz NL. Defects in cardiac function precede morphological abnormalities in fish embryos exposed to polycyclic aromatic hydrocarbons. Toxicol Appl Pharmacol 2004;196:191-205.

Incardona JP, Gardner LD, Linbo TL, Brown TL, Esbaugh AJ, Mager EM, Stieglitz JD, French BL, Labenia JS, Laetz CA, Tagal M, Sloan CA, Elizur A, Benetti DD, Grosell M, Block BA, Scholz NL. Deepwater Horizon crude oil impacts the developing hearts of large predatory pelagic fish. Proc Natl Acad Sci 2014;111:E1510-E1518. 
Incardona JP, Linbo TL, Scholz NL. Cardiac toxicity of 5-ring polycyclic aromatic hydrocarbons is differentially dependent on the aryl hydrocarbon receptor 2 isoform during zebrafish development. Toxicol Appl Pharmacol 2011;257:242-249.

Johnson LL, Casillas E, Collier TK, McCain BB, Varanasi U. Contaminant effects on ovarian development in English sole (Parophrys vetulus) from Puget Sound, Washington. Can J Fish Aquat Sci 1988;45:2133-2146.

Johnson LL, Collier TK, Stein JE. An analysis in support of sediment quality thresholds for polycyclic aromatic hydrocarbons (PAHs) to protect estuarine fish. Aquat Conserv Mar Freshw Ecosyst 2002;12:517-538.

Jonsson G, Bechmann RK, Bamber SD, Baussant T. Bioconcentration, biotransformation, and elimination of polycyclic aromatic hydrocarbons in sheepshead minnows (Cyprinodon variegatus) exposed to contaminated seawater. Environ Toxicol Chem 2004;23:1538-1548.

Kimmel CB, Ballard WW, Kimmel SR, Ullmann B, Schilling TF. Stages of embryonic development of the zebrafish. Dev Dyn 1995;203:253-310.

Kokel D, Bryan J, Laggner C, White R, Cheung CYJ, Mateus R, Healey D, Kim S, Werdich AA, Haggarty SJ, Macrae CA, Shoichet B, Peterson RT. Rapid behavior-based identification of neuroactive small molecules in the zebrafish. Nat Chem Biol 2010;6:231-237.

Laflamme RE, Hites RA. The global distribution of polycyclic aromatic hydrocarbons in recent sediments. Geochim Cosmochim Acta 1978;42:289-303.

Lammer E, Carr GJ, Wendler K, Rawlings JM, Belanger SE, Braunbeck T. Is the fish embryo toxicity test (FET) with the zebrafish (Danio rerio) a potential alternative for the fish acute toxicity test? Comp Biochem Physiol Part C, Pharmacol Toxicol Endocrinol 2009;149:196-209. 
Larcher T, Perrichon P, Vignet C, Ledevin M, Le Menach K, Lyphout L, Landi L, Clerandeau C, Lebihanic F, Ménard D, Burgeot T, Budzinski H, Akcha F, Cachot J, Cousin X. Chronic dietary exposure of zebrafish to PAH mixtures results in carcinogenic but not genotoxic effects. Environ Sci Pollut Res 2014;21:13833-13849.

Le Bihanic F, Sommard V, de Lansalut P, Pichon A, Grasseta J, Berradab S, Budzinski H, Cousin X, Morin B, Cachot J. Environmental concentrations of benz[a]anthracene induce developmental defects and DNA damage and impair photomotor response in Japanese medaka larvae. Ecotoxicol Environ Saf 2015;321-328.

Lee RF, Sauerheber R, Dobbs GH. Uptake, metabolism and discharge of polycyclic aromatic hydrocarbons by marine fish. Mar Biol 1972;17:201-208.

Linney E, Upchurch L, Donerly S. Zebrafish as a neurotoxicological model. Neurotoxicol Teratol 2004;26:709-718.

Lucas J, Perrichon P, Nouhaud M, Audras A, Leguen I, Lefrancois C. Aerobic metabolism and cardiac activity in the descendants of zebrafish exposed to pyrolytic polycyclic aromatic hydrocarbons. Environ Sci Pollut Res 2014;21:13888-13897.

MacPhail RC, Brooks J, Hunter DL, Padnos B, Irons TD, Padilla S. Locomotion in larval zebrafish: Influence of time of day, lighting and ethanol. Neurotoxicology 2009;30:52-58.

Mazéas O, Budzinski H. Solid-phase extraction and purification for the quantification of polycyclic aromatic hydrocarbon metabolites in fish bile. Anal Bioanal Chem 2005;383:985-990.

Mccormick MI. Experimental test of the effect of maternal hormones on larval quality of a coral reef fish. Oecologia 1999; 18:412-422.

Meador JP, Stein JE, Reichert WL, Varanasi U. Bioaccumulation of polycyclic aromatic hydrocarbons by marine organisms. Rev Environ Contam Toxicol 1995;143:79-165. 
Middaugh DP, Chapman PJ, Shelton ME. Responses of embryonic and larval inland silversides, Menidia beryllina, to a water-soluble fraction formed during biodegradation of artificially weathered Alaska North Slope crude oil. Arch Environ Contam Toxicol 1996;31:410-419.

Middaugh DP, Shelton ME, Mckenney CL, Cherr G, Chapman PJ, Courtney LA. Preliminary observations on responses of embryonic and larval pacific herring, Clupea pallasi, to neutral fraction biodegradation products of weathered Alaska north slope oil. Arch Environ Contam Toxicol 1998;196:188-196.

Milinkovitch T, Lucas J, Le Floch S, Thomas-Guyon H, Lefrançois C. Effect of dispersed crude oil exposure upon the aerobic metabolic scope in juvenile golden grey mullet (Liza aurata). Mar Pollut Bull 2012;64:865-71.

Milinkovitch T, Thomas-Guyon H, Lefrançois C, Imbert N. Dispersant use as a response to oil spills: toxicological effects on fish cardiac performance. Fish Physiol Biochem 2013;39:257-262.

Monteiro PRR, Reis-Henriques MA, Coimbra J. Plasma steroid levels in female flounder (Platichthys flesus) after chronic dietary exposure to single polycyclic aromatic hydrocarbons. Mar Environ Res 2000a;49:453-467.

Monteiro PRR, Reis-Henriques MA, Coimbra J. Polycyclic aromatic hydrocarbons inhibit in vitro ovarian steroidogenesis in the flounder (Platichthys flesus L.). Aquat Toxicol 2000b;48:549-559.

Nagler JJ, Cyr DG. Exposure of male american plaice (Hippoglossoides platessoides) to contaminated marine sediments decreases the hatching success of their progeny. Environ Toxicol Chem 1997;16:1733-1738.

Neff JM. Polycyclic aromatic hydrocarbons in the aquatic environment: sources, fates and biological applied. Science Publishers, UK 
Nye JA, Davis DD, Miller TJ. The effect of maternal exposure to contaminated sediment on the growth and condition of larval Fundulus heteroclitus. Aquat Toxicol 2007;82:242-250.

Van der Oost R, Beyer J, Vermeulen NPE. Fish bioaccumulation and biomarkers in environmental risk assessment: a review. Environ Toxicol Pharmacol 2003;13:57-149.

Padilla S, Hunter DL, Padnos B, Frady S, MacPhail RC. Assessing locomotor activity in larval zebrafish: Influence of extrinsic and intrinsic variables. Neurotoxicol Teratol 2011;33:624630.

Palmork KH, Solbakken JE. Distribution and elimination of [9-14C]Phenanthrene in the Horse mussel (Modiola modiolus). Bull Environ Contam Toxicol 1981;26:196-201.

Péan S, Daouk T, Vignet C, Lyphout L, Leguay D, Loizeau V, Bégout M-L, Cousin X. Longterm dietary-exposure to non-coplanar PCBs induces behavioral disruptions in adult zebrafish and their offspring. Neurotoxicol Teratol 2013;39:45-56.

Perrichon P, Le Bihanic F, Bustamante P, Le Menach K, Budzinski H, Cachot J, Cousin X. Influence of sediment composition on PAH toxicity using zebrafish (Danio rerio) and Japanese medaka (Oryzias latipes) embryo-larval assays. Environ Sci Pollut Res 2014;21:13703-13719.

Peterson CH, Rice SD, Short JW, Esler D, Bodkin JL, Ballachey BE, Irons DB. Long-term ecosystem response to the Exxon Valdez oil spill. Science (80- ) 2003;302:2082-2086.

Pollino CA, Georgiades E, Holdway DA. Physiological changes in reproductively active rainbowfish (Melanotaenia fluviatilis) following exposure to naphthalene. Ecotoxicol Environ Saf 2009;72:1265-1270.

Sakari M. Depositional history of polycyclic aromatic hydrocarbons : reconstruction of petroleum pollution record in peninsular Malaysia. Org. Pollut. Ten Years After Stock. Conv. Environ. Anal. Updat;6:135-142. 
Schneider C a, Rasband WS, Eliceiri KW. NIH Image to ImageJ: 25 years of image analysis. Nat Methods 2012;9:671-675.

Shen H, Huang Y, Wang R, Zhu D, Li W, Shen G, Wang B, Zhang Y, Chen Y, Lu Y, Chen H, Li T, Sun K, Li B, Liu W, Liu J, Tao S. Global atmospheric emissions of polycyclic aromatic hydrocarbons from 1960 to 2008 and future predictions. Environ Sci Technol $2013 ; 47: 6415-6424$.

Strmac M, Oberemm A, Braunbeck T. Effects of sediment eluates and extracts from differently polluted small rivers on zebrafish embryos and larvae. J Fish Biol 2002;61:24-38.

Thomas P, Budiantara L. Reproductive life history stages sensitive to oil and naphthalene in Atlantic croaker. Mar Environ Res 1995;39:147-150.

Thomas P. Teleost model for studying the effects of chemicals on female reproductive endocrine function. J Exp Zool Suppl 1990;4:126-128.

Tilghman Hall A, Oris JT. Anthracene reduces reproductive potential and is maternally transferred during long-term exposure in fathead minnows. Aquat Toxicol 1991;19:249264.

Varanasi U, Reichert WL, Stein JE, Brown DW, Sanborn HR. Bioavailability and biotransformation of aromatic hydrocarbons in benthic organisms exposed to sediment from an urban estuary. Environ Sci Technol 1985;19:836-841.

Vicquelin L, Leray-Forget J, Peluhet L, LeMenach K, Deflandre B, Anschutz P, Etcheber H, Morin B, Budzinski H, Cachot J. A new spiked sediment assay using embryos of the Japanese medaka specifically designed for a reliable toxicity assessment of hydrophobic chemicals. Aquat Toxicol 2011;105:235-245.

Vignet C, Le Menach K, Mazurais D, Lucas J, Perrichon P, Le Bihanic F, Devier M-H, Lyphout L, Frère L, Bégout M-L, Zambonino-Infante J-L, Budzinski H, Cousin X. Chronic dietary 
exposure to pyrolytic and petrogenic mixtures of PAHs causes physiological disruption in zebrafish - Part I: Survival and growth. Environ Sci Pollut Res 2014;21:13804-13817.

Vignet C. Altération de la physiologie des poissons exposés à des hydrocarbures aromatiques polycyliques (HAP) : Comportement et reproduction. Université de La Rochelle. Thesis (in French)-360p.

Wessel N, Ménard D, Pichavant-Rafini K, Ollivier H, Le Goff J, Burgeot T, Akcha F. Genotoxic and enzymatic effects of fluoranthene in microsomes and freshly isolated hepatocytes from sole (Solea solea). Aquat Toxicol 2012;108:33-41.

Wessel N, Santos R, Menard D, Le Menach K, Buchet V, Lebayon N, Loizeau V, Burgeot T, Budzinski H, Akcha F. Relationship between PAH biotransformation as measured by biliary metabolites and EROD activity, and genotoxicity in juveniles of sole (Solea solea). Mar Environ Res 2010;69:S71-S73.

Zar JH. Biostatistical analysis, 5th ed. Pe. Upper Saddle River, New Jersey 


\section{Captions for the figures}

Fig. 1. Hatching kinetic in 120 hpf offspring larvae originating from (A) PY, (B) BAL and (C) HFO-exposed parents. Values are means \pm SEM, nd = no data available. Letters denote significant differences between concentrations at different hatching times $(\mathrm{P}<0.05)$.

Fig. 2. Behavioral performance in $120 \mathrm{hpf}$ offspring larvae originating from (A) PY, (B) BAL and (C) HFO-exposed parents following a light/dark challenge. Values are means distance moved \pm SEM per 5-min intervals, $\mathrm{nd}=$ no data available. Lower and upper cases denote significant differences between concentrations and light/dark phases (Light On (1), Dark and Light On (2)) respectively.

Fig. 3. Cardiac activity in 120 hpf offspring larvae from PY, BAL, HFO-exposed parents. Values are means $\pm \mathrm{SEM}, \mathrm{nd}=$ no data available. Letters denote significant differences between concentrations $(\mathrm{P}<0.05)$.

Fig. 4. In vivo EROD activity in $96 \mathrm{hpf}$ offspring larvae originating from PY, BAL and HFOexposed parents. Values are expressed in response factor compared to respective Solvent Control, $\mathrm{nd}=$ no data available. No significant difference was observed $(\mathrm{P}>0.05)$.

Fig. 5. DNA strand break levels in 24 hpf offspring embryos originating from (A) $P Y(N=4),(B)$ BAL $(\mathrm{N}=3)$ and $(\mathrm{C})$ HFO $(\mathrm{N}=3)$ exposed parents. Boxes denote SEM and vertical bars denote $95 \%$ confidence interval, nd $=$ no data available. No significant difference was observed $(\mathrm{P}>0.05)$. 
Fig. 1 Supplementary data. Concentrations $\left(\mu \mathrm{g} \cdot \mathrm{g}^{-1}\right)(\mathrm{A})$ and relative proportion (\%) (B) of PAHs in the three aromatic fractions (PY, BAL, HFO). 


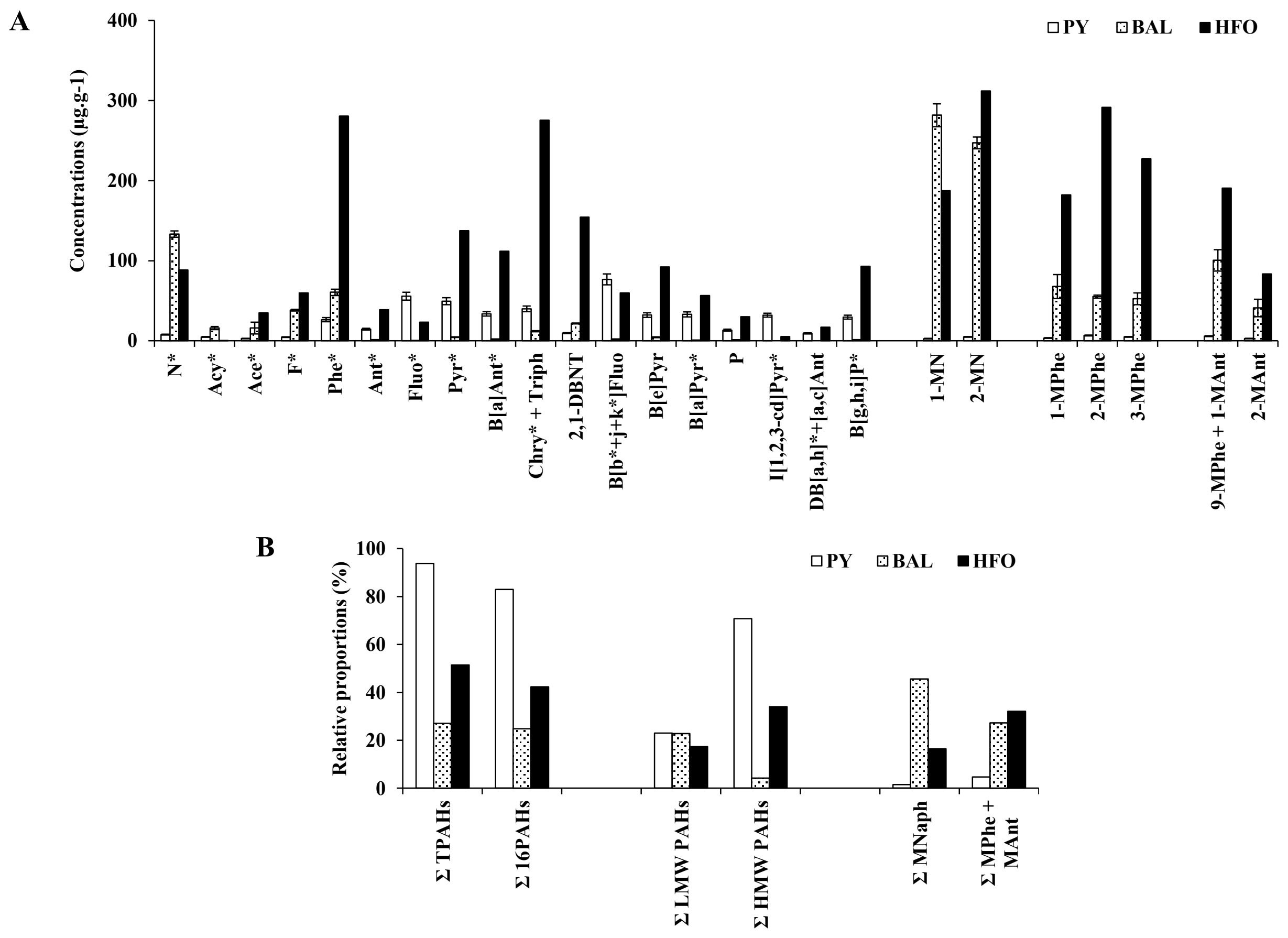

Figure 1 Supplementary data 
Figure 1

A

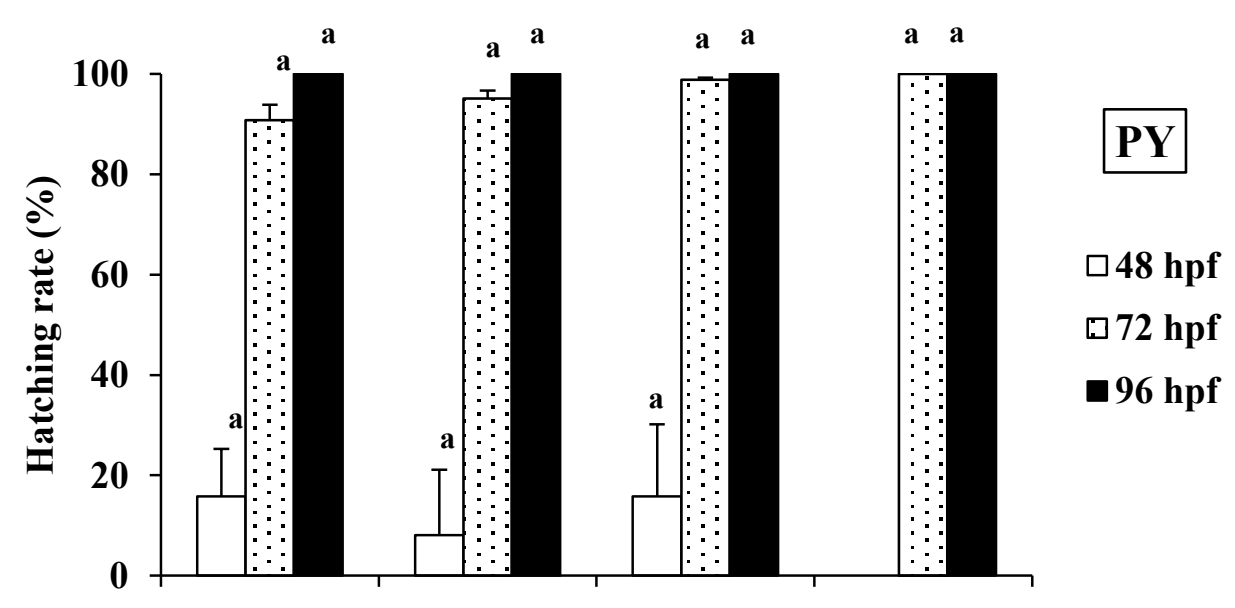

B

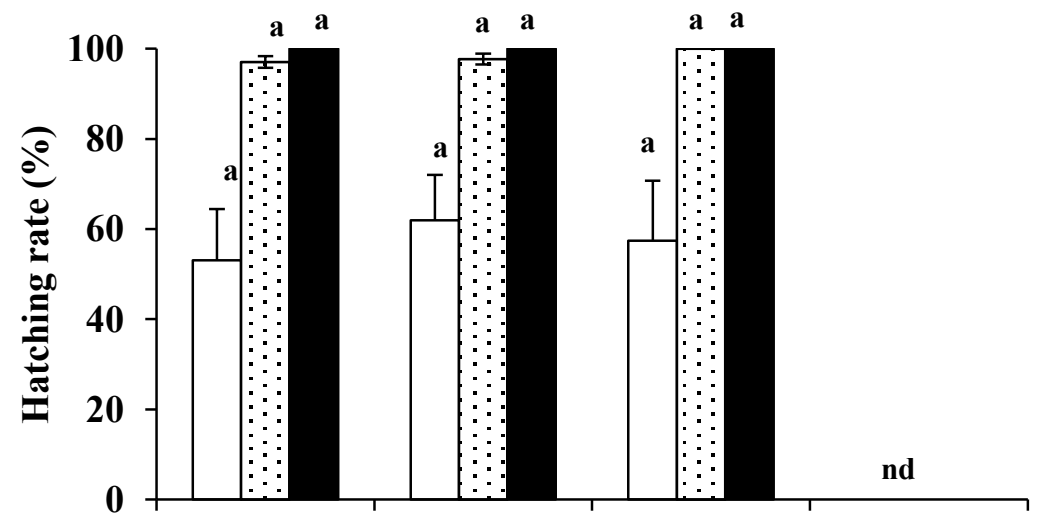

$$
\text { BAL }
$$

$\square 48$ hpf

$\square 72$ hpf

$\square 96$ hpf

C

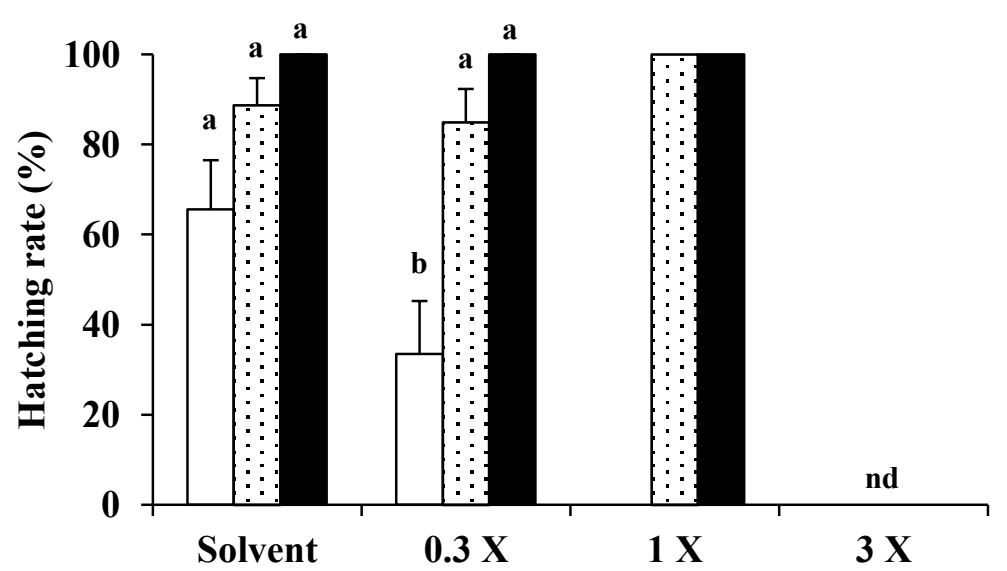

$\square 48$ hpf

$972 \mathrm{hpf}$

096 hpf 
Figure 2
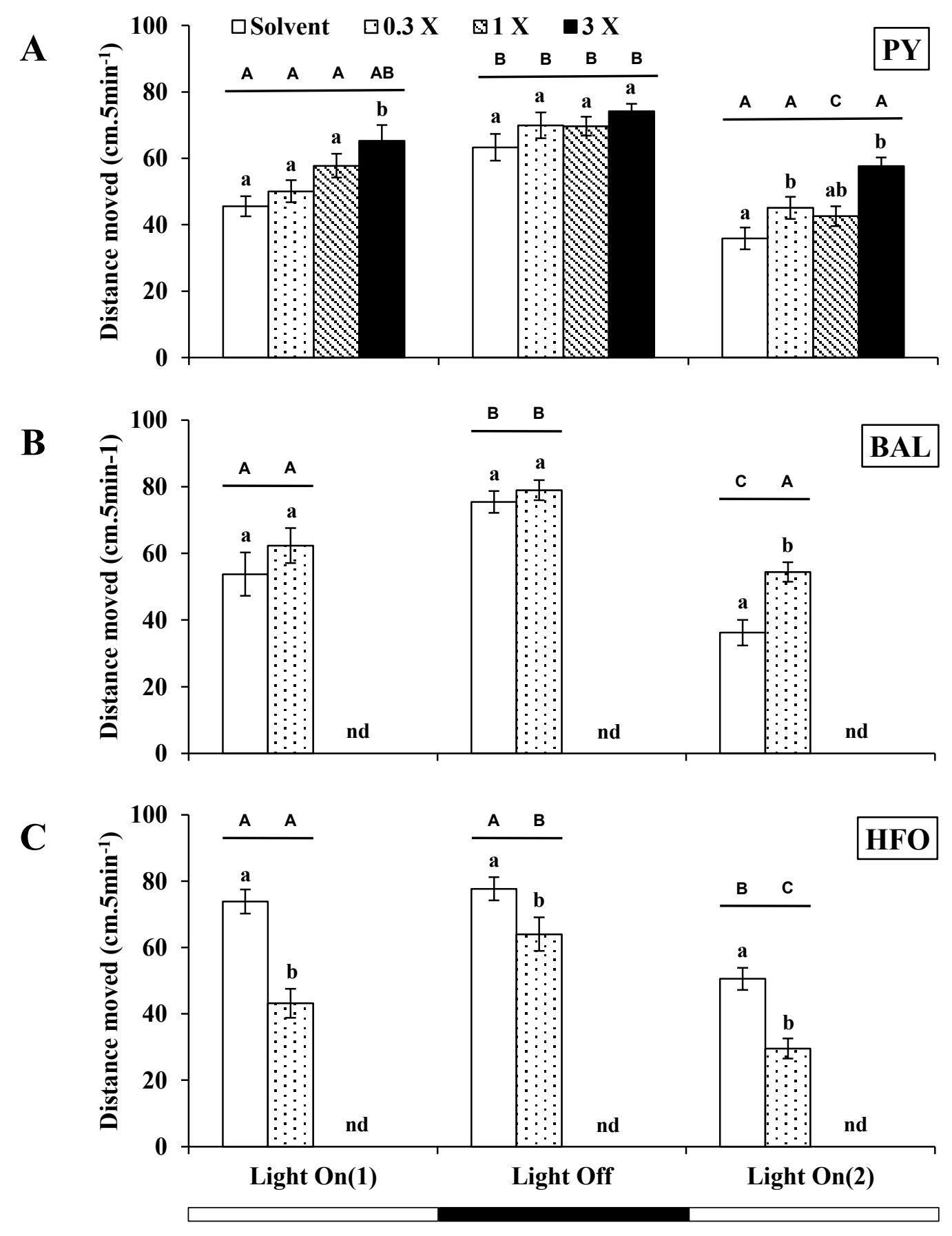
Figure 3

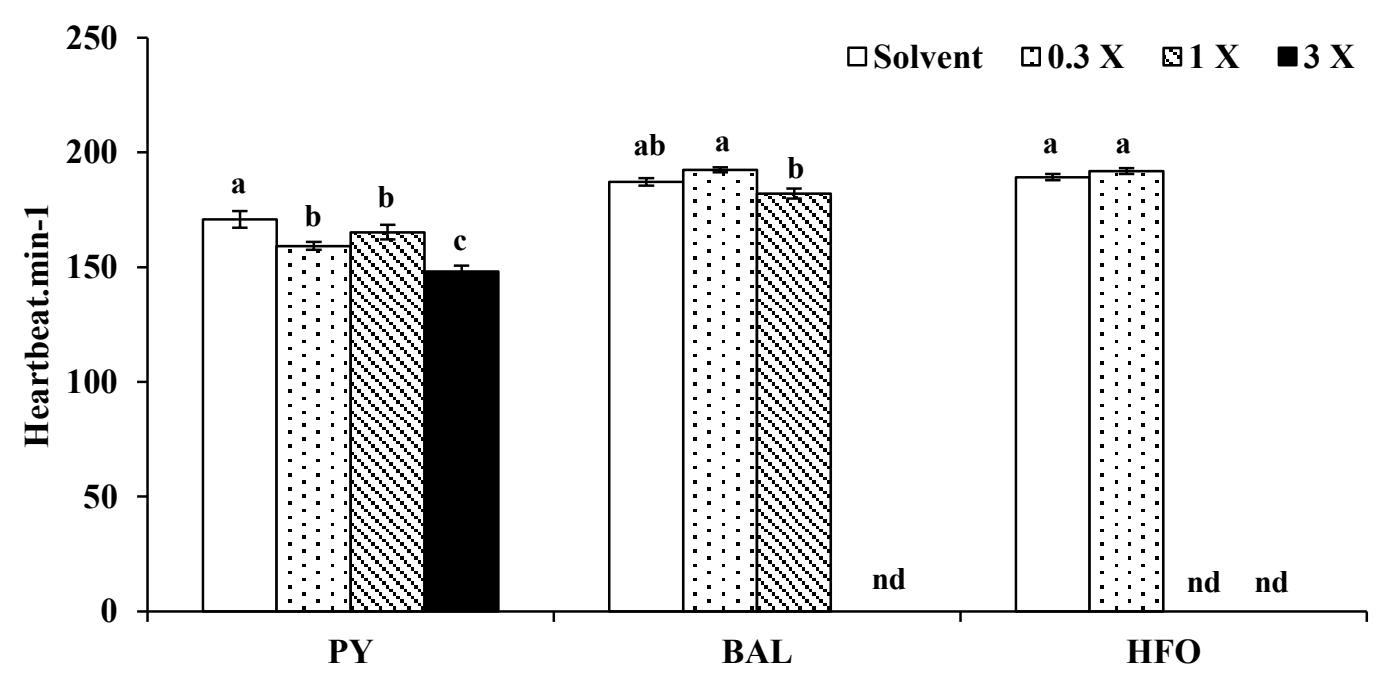


Figure 4

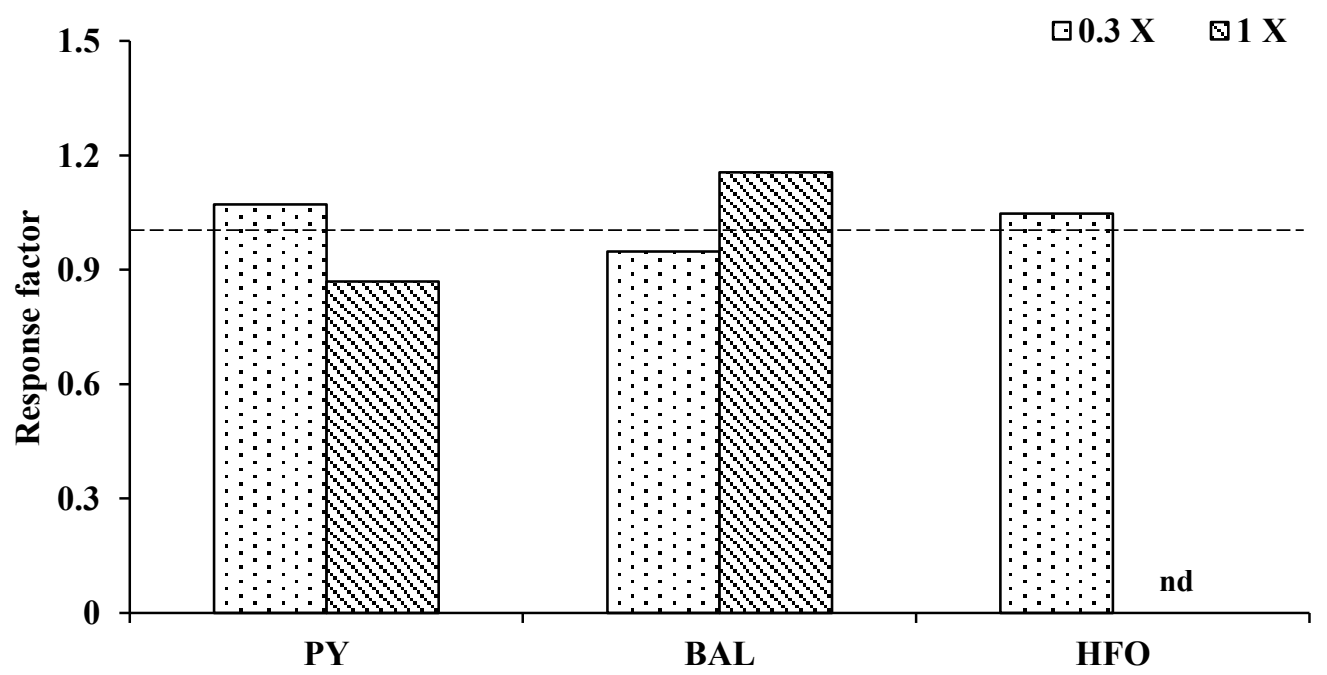


Figure 5

- Mean $\square$ Mean \pm SE I Mean $\pm 0,95$ Conf. Interval
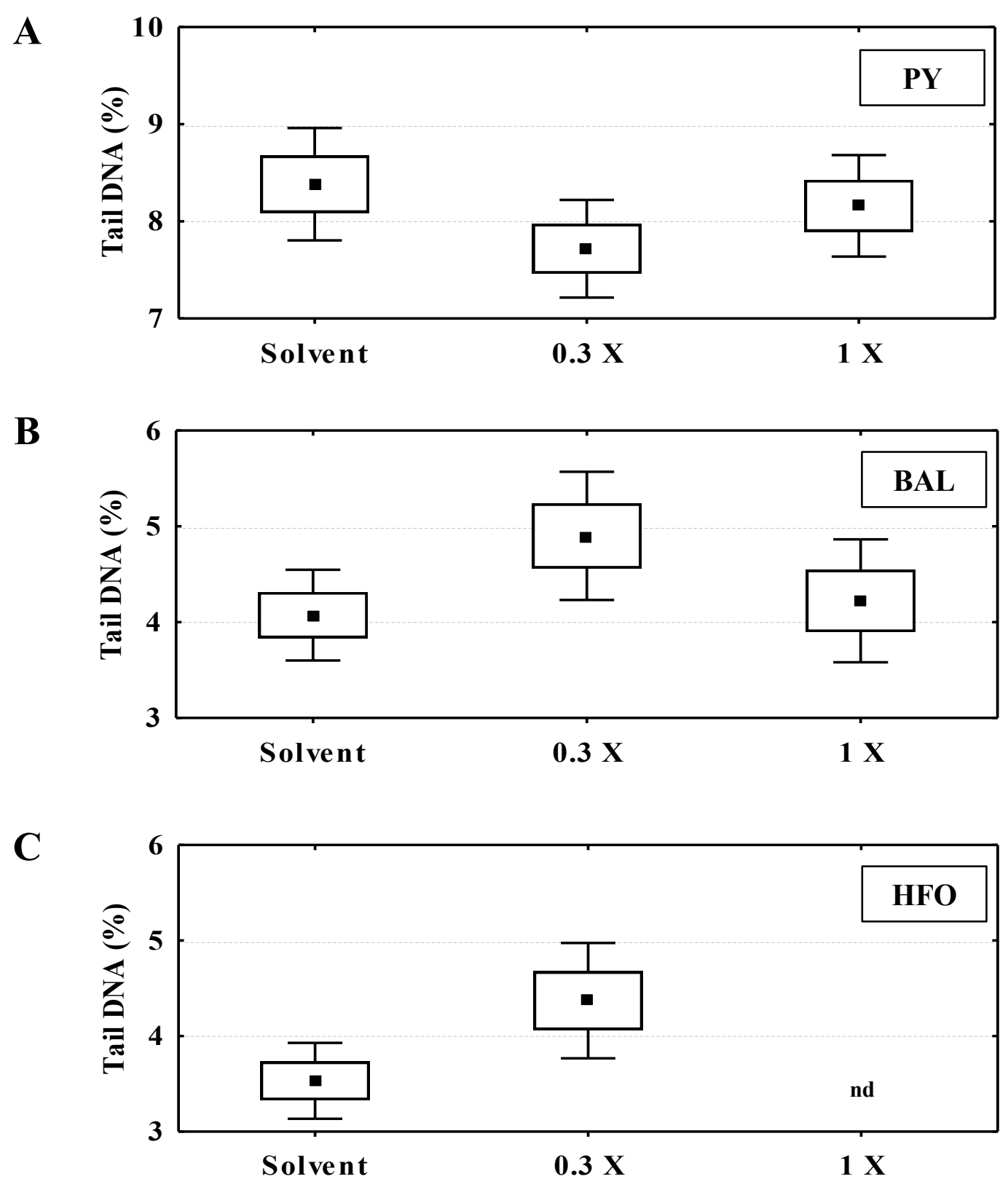
Table 1 Supplementary data

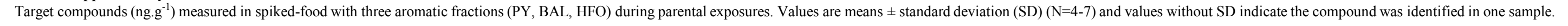

\begin{tabular}{|c|c|c|c|c|c|c|c|c|c|c|c|c|c|}
\hline & & \multirow{2}{*}{\multicolumn{4}{|c|}{ PY Aromatic Fraction }} & \multirow{2}{*}{\multicolumn{4}{|c|}{ BAL Aromatic Fraction }} & \multirow{2}{*}{\multicolumn{4}{|c|}{ HFO Aromatic Fraction }} \\
\hline & & & & & & & & & & & & & \\
\hline Compounds & $\begin{array}{l}\text { Molecular } \\
\text { Weight } \\
\left(\text { g.mol }{ }^{-1}\right)\end{array}$ & Solvent & $0.3 \mathrm{X}$ & $1 \mathrm{X}$ & $3 x$ & Solvent & $0.3 \mathrm{X}$ & $1 \mathrm{X}$ & $3 x$ & Solvent & $0.3 \mathrm{X}$ & $1 \mathrm{X}$ & $3 X$ \\
\hline Naphthalene* & 128 & $\overline{6 \pm 6}$ & $15 \pm 7$ & $56 \pm 14$ & $157 \pm 74$ & $\overline{3 \pm 1}$ & $161 \pm 21$ & $315 \pm 183$ & $1110 \pm 472$ & $\overline{4 \pm 1}$ & $37 \pm 6$ & $120 \pm 16$ & $405 \pm 73$ \\
\hline 1-Methylnaphthalene & 142 & $4 \pm 6$ & $8 \pm 2$ & $22 \pm 5$ & $62 \pm 21$ & $2 \pm 0$ & $458 \pm 19$ & $1147 \pm 102$ & $3300 \pm 739$ & $2 \pm 0$ & $86 \pm 8$ & $261 \pm 20$ & $854 \pm 84$ \\
\hline 2-Methylnaphthalene & 142 & $8 \pm 9$ & $15 \pm 3$ & $43 \pm 8$ & $116 \pm 39$ & $4 \pm 1$ & $420 \pm 19$ & $1036 \pm 96$ & $2982 \pm 725$ & $4 \pm 1$ & $137 \pm 13$ & $396 \pm 32$ & $1259 \pm 118$ \\
\hline$\sum$ Methylnapththalene & 142 & $12 \pm 15$ & $23 \pm 5$ & $65 \pm 13$ & $178 \pm 60$ & $5 \pm 1$ & $878 \pm 38$ & $2183 \pm 197$ & $6282 \pm 1465$ & $6 \pm 2$ & $223 \pm 20$ & $657 \pm 52$ & $2113 \pm 201$ \\
\hline Acenaphtylene* & 152 & $1 \pm 0$ & $11 \pm 2$ & $35 \pm 6$ & $114 \pm 23$ & $1 \pm 0$ & $15 \pm 1$ & $46 \pm 2$ & $136 \pm 19$ & $1 \pm 0$ & $3 \pm 1$ & $3 \pm 1$ & $13 \pm 13$ \\
\hline Acenaphtene* & 154 & $2 \pm 1$ & $14 \pm 12$ & $29 \pm 7$ & $89 \pm 24$ & $23 \pm 21$ & $37 \pm 26$ & $67 \pm 68$ & $90 \pm 30$ & $27 \pm 26$ & $46 \pm 23$ & $74 \pm 19$ & $190 \pm 17$ \\
\hline Fluorene* & 166 & $2 \pm 1$ & $14 \pm 3$ & $42 \pm 8$ & $137 \pm 28$ & $2 \pm 1$ & $79 \pm 1$ & $232 \pm 2$ & $677 \pm 55$ & $2 \pm 1$ & $34 \pm 2$ & $99 \pm 8$ & $312 \pm 25$ \\
\hline Phenanthrene* & 178 & $8 \pm 4$ & $95 \pm 21$ & $291 \pm 60$ & $895 \pm 213$ & $6 \pm 4$ & $178 \pm 7$ & $492 \pm 10$ & $1438 \pm 86$ & $6 \pm 3$ & $152 \pm 7$ & $418 \pm 32$ & $1279 \pm 51$ \\
\hline 1-Methylphenanthrene & 192 & $1 \pm 0$ & $12 \pm 3$ & $37 \pm 11$ & $100 \pm 28$ & $1 \pm 0$ & $122 \pm 4$ & $348 \pm 14$ & $956 \pm 97$ & $0 \pm 0$ & $73 \pm 8$ & $227 \pm 15$ & $617 \pm 71$ \\
\hline 2-Methylphenanthrene & 192 & $2 \pm 0$ & $19 \pm 5$ & $60 \pm 13$ & $175 \pm 41$ & $1 \pm 0$ & $121 \pm 2$ & $340 \pm 16$ & $915 \pm 124$ & $1 \pm 0$ & $149 \pm 11$ & $400 \pm 28$ & $1172 \pm 166$ \\
\hline 3-Methylphenanthrene & 192 & $2 \pm 1$ & $17 \pm 3$ & $47 \pm 11$ & $149 \pm 31$ & $1 \pm 0$ & $114 \pm 14$ & $319 \pm 38$ & $850 \pm 156$ & $1 \pm 0$ & $126 \pm 24$ & $326 \pm 47$ & $934 \pm 160$ \\
\hline$\sum$ Methylphenanthrene & 192 & $7 \pm 3$ & $70 \pm 15$ & $218 \pm 41$ & $668 \pm 157$ & $2 \pm 2$ & $640 \pm 35$ & $1804 \pm 67$ & $4957 \pm 731$ & $2 \pm 2$ & $530 \pm 34$ & $1448 \pm 144$ & $4122 \pm 581$ \\
\hline Anthracene* & 178 & $1 \pm 0$ & $49 \pm 13$ & $159 \pm 41$ & $482 \pm 165$ & $0 \pm 0$ & $2 \pm 1$ & $4 \pm 1$ & $42 \pm 54$ & $0 \pm 0$ & $22 \pm 1$ & $70 \pm 2$ & $220 \pm 10$ \\
\hline 2-Methylanthracene & 192 & $0 \pm 0$ & $8 \pm 2$ & $25 \pm 6$ & $78 \pm 18$ & blq & blq & blq & $32 \pm 8$ & blq & blq & blq & $409 \pm 32$ \\
\hline 9-Methylphenanthrene +2 -Methylanthracene & 192 & $1 \pm 0$ & $14 \pm 4$ & $49 \pm 12$ & $165 \pm 56$ & $1 \pm 0$ & $283 \pm 29$ & $798 \pm 42$ & $2226 \pm 394$ & $1 \pm 0$ & $137 \pm 20$ & $360 \pm 85$ & $990 \pm 206$ \\
\hline Dibenzo[b,d]thiophene & 184 & $2 \pm 3$ & $11 \pm 1$ & $34 \pm 5$ & $102 \pm 26$ & $0 \pm 0$ & $443 \pm 8$ & $1161 \pm 18$ & $3489 \pm 208$ & $0 \pm 0$ & $54 \pm 3$ & $166 \pm 11$ & $546 \pm 54$ \\
\hline 2,1-Dibenzonaphthothiophene & 234 & $5 \pm 3$ & $52 \pm 26$ & $156 \pm 70$ & $472 \pm 230$ & 0 & $66 \pm 1$ & $194 \pm 9$ & $588 \pm 30$ & 0 & $56 \pm 4$ & $186 \pm 8$ & $573 \pm 36$ \\
\hline Fluoranthene* & 202 & $3 \pm 3$ & $130 \pm 28$ & $523 \pm 182$ & $1782 \pm 353$ & $2 \pm 1$ & $2 \pm 2$ & $1 \pm 1$ & $15 \pm 17$ & $2 \pm 1$ & $17 \pm 1$ & $44 \pm 2$ & $145 \pm 18$ \\
\hline Pyrene* & 202 & $3 \pm 3$ & $112 \pm 24$ & $447 \pm 160$ & $1496 \pm 311$ & $2 \pm 0$ & $13 \pm 2$ & $18 \pm 2$ & $73 \pm 28$ & $1 \pm 0$ & $80 \pm 3$ & $227 \pm 19$ & $709 \pm 64$ \\
\hline Benzo[a]anthracene* & 228 & $1 \pm 0$ & $171 \pm 75$ & $581 \pm 221$ & $1671 \pm 763$ & 0 & $4 \pm 1$ & $14 \pm 2$ & $49 \pm 28$ & 0 & $57 \pm 4$ & $172 \pm 11$ & $543 \pm 29$ \\
\hline Chrysene + Triphenylene* & 228 & $1 \pm 0$ & $215 \pm 91$ & $744 \pm 290$ & $2144 \pm 1032$ & blq & $30 \pm 1$ & $98 \pm 4$ & $320 \pm 62$ & blq & $108 \pm 8$ & $336 \pm 21$ & $1073 \pm 79$ \\
\hline Benzo $[\mathrm{b}+\mathrm{j}+\mathrm{k}]$ fluoranthene* & 252 & $2 \pm 1$ & $273 \pm 72$ & $868 \pm 220$ & $2740 \pm 674$ & 2.4 & $6 \pm 0$ & $20 \pm 1$ & $66 \pm 7$ & 2.4 & $32 \pm 2$ & $110 \pm 8$ & $363 \pm 18$ \\
\hline Benzo[e]pyrene & 252 & $1 \pm 0$ & $109 \pm 29$ & $346 \pm 86$ & $1084 \pm 286$ & blq & $17 \pm 0$ & $52 \pm 1$ & $160 \pm 10$ & blq & $56 \pm 3$ & $173 \pm 11$ & $536 \pm 26$ \\
\hline Benzo[a]pyrene* & 252 & $1 \pm 0$ & $118 \pm 33$ & $373 \pm 95$ & $1168 \pm 346$ & $0 \pm 0$ & blq & $4 \pm 1$ & $17 \pm 3$ & $0 \pm 0$ & blq & $108 \pm 6$ & $342 \pm 10$ \\
\hline Indeno[1,2,3-cd]pyrene* & 276 & $0 \pm 0$ & $123 \pm 41$ & $349 \pm 89$ & $1188 \pm 265$ & blq & blq & blq & blq & $\mathrm{blq}$ & blq & blq & $\mathrm{blq}$ \\
\hline Benzo[g,h,i]perylene* & 276 & $0 \pm 0$ & $87 \pm 27$ & $268 \pm 67$ & $893 \pm 191$ & $0 \pm 0$ & blq & $12 \pm 0$ & $42 \pm 12$ & $0 \pm 0$ & blq & $146 \pm 10$ & $481 \pm 12$ \\
\hline Benzo[g,h,i]perylene* & 276 & $1 \pm 0$ & $37 \pm 9$ & $121 \pm 27$ & $390 \pm 83$ & $0 \pm 0$ & blq & $5 \pm 1$ & $13 \pm 1$ & $0 \pm 0$ & blq & $56 \pm 4$ & $172 \pm 14$ \\
\hline $\operatorname{Dibenzo}[\mathrm{a}, \mathrm{h}]+[\mathrm{a}, \mathrm{c}]$ anthracene* & 278 & $2 \pm 2$ & $32 \pm 11$ & $108 \pm 43$ & $301 \pm 106$ & 0.3 & blq & $3 \pm 1$ & $11 \pm 1$ & 0.3 & blq & $34 \pm 2$ & $113 \pm 6$ \\
\hline Sum of parent PAHs & & $34 \pm 6$ & $1670 \pm 448$ & $5532 \pm 1383$ & $17305 \pm 4798$ & $33 \pm 26$ & $1053 \pm 63$ & $2739 \pm 231$ & $8335 \pm 854$ & $39 \pm 30$ & $880 \pm 28$ & $2558 \pm 169$ & $8082 \pm 305$ \\
\hline Sum of total PAHs & & $55 \pm 12$ & $1763 \pm 468$ & $5816 \pm 1433$ & $18151 \pm 4983$ & $40 \pm 29$ & $2572 \pm 96$ & $6726 \pm 278$ & $19574 \pm 1945$ & $47 \pm 33$ & $1633 \pm 71$ & $4663 \pm 360$ & $14317 \pm 813$ \\
\hline
\end{tabular}

* Priority contaminants selected by the US Environmental Protection Agency (EPA)

blq : below limit of quantification 


\section{Table 1}

Specific primer sequences for the 11 target genes measured by real-time PCR.

\begin{tabular}{|c|c|c|c|}
\hline Target gene & Name & Accession Number & Primer $\left(5^{\prime} \rightarrow 3^{\prime}\right)$ \\
\hline$\overline{\text { gapdh }}$ & glyceraldehyde-3-phosphate dehydrogenase & BC083506 & GTGGAGTCTACTGGTGTCTTC/GTGCAGGAGGCATTGCTTACA \\
\hline$e e f 1$ & eukaryotic elongation factor 1 & NM_131263.1 & CAGCTGATCGTTGGAGTCAA/TGTATGCGCTGACTTCCTTG ${ }^{\mathrm{b}}$ \\
\hline Bactin & beta-actin & NM_131031 & CCCAGACATCAGGGAGTGATa/CACAATACCGTGCTCAATGGb \\
\hline cyp1A & cytochrome P4501A & ВС094977 & GACAGGCGCTCCTAAAACAG ${ }^{\mathrm{a} / C T G A A C G C C A G A C T C T T T C C ~}{ }^{\mathrm{b}}$ \\
\hline$a h r 2$ & aryl hydrocarbon receptor 2 & NM_131264 & GCCTGGGATAAAGGAGGAAG/CAGCTCCACCTGTCCAAAT $^{\mathrm{b}}$ \\
\hline cat & catalase & NM_-130912 & CGCTTCTGTTTCCGTCTTTC $^{\mathrm{a}} /$ CCCTGAGCATTGACCAGTTT $^{\mathrm{b}}$ \\
\hline $\operatorname{sod}(C u / Z n)$ & Cu/Zn-superoxide dismutase & $\mathrm{BC} 055516$ & GTTTCCACGTCCATGCTTTT $^{\mathrm{a}} /$ CGGTCACATTACCCAGGTCT $^{\mathrm{b}}$ \\
\hline $\operatorname{sod}(M n)$ & Mn-superoxide dismutase & CB923500 & GGCCAAGGGTGATGTGAC $^{\text {a/ACGCTTTATGGCCTCCAAC }}{ }^{\mathrm{b}}$ \\
\hline gpx4 & glutathione peroxidase 4 & NM_001007282.1 & AGGATCCAAGTGTGGTGGAG/aGGGTTTCCAAACAAACCTT ${ }^{\mathrm{b}}$ \\
\hline$p 53$ & bcl-2-binding component 3 & NM_131327.1 & GCTTGTCACAGGGGTCATTTª/ACAAAGGTCCCAGTGGAGTG \\
\hline bax & bcl-2-associates X protein & AF231015 & GGAGATGAGCTGGATGGAAA $/$ GAAAAGCGCCACAACTCTTC $^{\mathrm{b}}$ \\
\hline
\end{tabular}

Forward primer $^{\mathrm{a}} /$ Reverse primer $^{\mathrm{b}}$ 


\section{Table 2}

Number of total individuals sampled for different chemical and biological analysis. The number into brackets corresponds to the number of spawning events used as replicates. The Comet assay was realized from one spawning event, the replicate number corresponds to analysis replicates.

\begin{tabular}{|c|c|c|c|c|c|c|}
\hline \multirow{3}{*}{ Sampling point } & \multirow[b]{3}{*}{ Endpoints } & \multirow[b]{3}{*}{ Treatment } & \multirow{2}{*}{\multicolumn{4}{|c|}{ Concentrations }} \\
\hline & & & & & & \\
\hline & & & Solvent Control & $0.3 \mathrm{X}$ & $1 \mathrm{X}$ & $3 \mathrm{X}$ \\
\hline \multirow[t]{3}{*}{$48-96 \mathrm{hpf}$} & Hatching success & PY & $296(3)$ & $323(5)$ & $552(5)$ & $20(1)$ \\
\hline & & BAL & 2216(9) & $521(7)$ & $258(7)$ & nsa \\
\hline & & $\mathrm{HFO}$ & $620(6)$ & $596(6)$ & $4(1)$ & nsa \\
\hline \multirow[t]{3}{*}{$96 \mathrm{hpf}$} & Morphological analyses & PY & $190(4)$ & $172(5)$ & $175(5)$ & nsa \\
\hline & & BAL & $75(3)$ & $60(3)$ & $17(1)$ & nsa \\
\hline & & $\mathrm{HFO}$ & $85(4)$ & $85(4)$ & nsa & nsa \\
\hline \multirow[t]{3}{*}{$120 \mathrm{hpf}$} & PMR analyses & PY & $140(5)$ & $100(4)$ & $76(2)$ & $39(3)$ \\
\hline & & BAL & $37(3)$ & $35(3)$ & nsa & nsa \\
\hline & & $\mathrm{HFO}$ & $115(3)$ & $90(3)$ & nsa & nsa \\
\hline \multirow[t]{3}{*}{$120 \mathrm{hpf}$} & Heartbeat & PY & $35(3)$ & $52(3)$ & $48(3)$ & $26(1)$ \\
\hline & & BAL & $21(2)$ & $24(2)$ & $22(2)$ & nsa \\
\hline & & HFO & $15(2)$ & $23(2)$ & nsa & nsa \\
\hline \multirow[t]{3}{*}{$96 \mathrm{hpf}$} & EROD activity & PY & $40(2)$ & $32(2)$ & $40(2)$ & nsa \\
\hline & & BAL & $58(3)$ & $47(3)$ & $26(3)$ & nsa \\
\hline & & $\mathrm{HFO}$ & $60(2)$ & $34(2)$ & nsa & nsa \\
\hline \multirow[t]{3}{*}{$24 \mathrm{hpf}$} & Comet assay & PY & $5(4)^{*}$ & $5(4) *$ & $5(4) *$ & nsa \\
\hline & & BAL & $5(3)^{*}$ & $5(3)^{*}$ & $5(3)^{*}$ & nsa \\
\hline & & $\mathrm{HFO}$ & $5(3)^{*}$ & $5(3)^{*}$ & nsa & nsa \\
\hline \multirow[t]{3}{*}{$96 \mathrm{hpf}$} & Gene expression (RT-PCR) & PY & $20(8)^{*}$ & $20(3)^{*}$ & $20(6)^{*}$ & $20(5)^{*}$ \\
\hline & & BAL & $20(8)^{*}$ & $20(8)^{*}$ & $20(4)^{*}$ & nsa \\
\hline & & HFO & $20(8)^{*}$ & $20(8)^{*}$ & $20(4)^{*}$ & nsa \\
\hline \multirow[t]{3}{*}{$120 \mathrm{hpf}$} & PAHs metabolites & PY & $50(3)^{*}$ & $50(3)^{*}$ & $50(3)^{*}$ & $50(3)^{*}$ \\
\hline & & BAL & $50(3)^{*}$ & $50(3)^{*}$ & nsa & nsa \\
\hline & & $\mathrm{HFO}$ & $50(3)^{*}$ & $50(3) *$ & nsa & nsa \\
\hline
\end{tabular}

* Individuals pooled for analysis; nsa: no sample available. 
Table 3

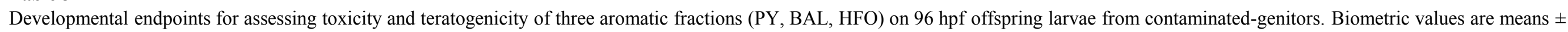
SEM.

\begin{tabular}{|c|c|c|c|c|c|c|c|c|}
\hline & \multirow{2}{*}{\multicolumn{3}{|c|}{ PY }} & \multirow{2}{*}{\multicolumn{3}{|c|}{ BAL }} & \multirow{2}{*}{\multicolumn{2}{|c|}{$\mathrm{HFO}$}} \\
\hline & & & & & & & & \\
\hline & Solvent & $0.3 \mathrm{X}$ & $1 \mathrm{X}$ & Solvent & $0.3 \mathrm{X}$ & $1 \mathrm{X}$ & Solvent & $0.3 \mathrm{X}$ \\
\hline & $\mathrm{N}=4 ; \mathrm{n}=190$ & $\mathrm{~N}=5 ; \mathrm{n}=172$ & $\mathrm{~N}=5 ; \mathrm{n}=175$ & $\mathrm{~N}=3 ; \mathrm{n}=75$ & $\mathrm{~N}=3 ; \mathrm{n}=60$ & $\mathrm{~N}=1 ; \mathrm{n}=17$ & $\mathrm{~N}=4 ; \mathrm{n}=85$ & $\mathrm{~N}=4 ; \mathrm{n}=85$ \\
\hline Standard length (mm) & $3.58 \pm 0.009^{\mathrm{a}}$ & $3.63 \pm 0.009^{b}$ & $3.57 \pm 0.012^{\mathrm{a}}$ & $3.55 \pm 0.018^{\mathrm{a}}$ & $3.57 \pm 0.022^{\mathrm{a}}$ & 3.61 & $3.48 \pm 0.023^{\mathrm{a}}$ & $3.59 \pm 0.014^{\mathrm{b}}$ \\
\hline Yolk sac surface $\left(\mathrm{mm}^{2}\right)$ & $0.26 \pm 0.002^{\mathrm{a}}$ & $0.24 \pm 0.002^{b}$ & $0.25 \pm 0.002^{\mathrm{c}}$ & $0.27 \pm 0.0026^{\mathrm{a}}$ & $0.27 \pm 0.006^{\mathrm{a}}$ & 0.32 & $0.28 \pm 0.005^{\mathrm{a}}$ & $0.29 \pm 0.003^{\mathrm{a}}$ \\
\hline Ratio Yolk sac/Whole larval surface & $0.229 \pm 0.001^{\mathrm{a}}$ & $0.213 \pm 0.001^{\mathrm{b}}$ & $0.216 \pm 0.002^{\mathrm{c}}$ & $0.224 \pm 0.004^{\mathrm{a}}$ & $0.224 \pm 0.005^{\mathrm{a}}$ & 0.265 & $0.241 \pm 0.004^{\mathrm{a}}$ & $0.236 \pm 0.002^{\mathrm{a}}$ \\
\hline Abnormal individuals (\%) & $6.34 \pm 1.58^{\mathrm{a}}$ & $11.1 \pm 2.20^{\mathrm{a}}$ & $8.48 \pm 3.03^{\mathrm{a}}$ & $21.9 \pm 2.01^{\mathrm{a}}$ & $25.9 \pm 2.26^{\mathrm{a}}$ & 0.00 & $19.8 \pm 5.13^{\mathrm{a}}$ & $18.0 \pm 3.50^{\mathrm{a}}$ \\
\hline \multicolumn{9}{|l|}{ Severity of abnormality (Scoring/3) $(\%)$ : } \\
\hline No affected (Score 0$)$ & $93.7 \pm 1.58$ & $88.9 \pm 2.20$ & $91.5 \pm 3.03$ & $78.1 \pm 2.01$ & $74.1 \pm 2.26$ & 100.0 & $80.3 \pm 5.13$ & $81.0 \pm 4.25$ \\
\hline Mild (Score 1) & $5.24 \pm 1.63$ & $9.12 \pm 2.07$ & $5.28 \pm 2.04$ & $18.9 \pm 0.86$ & $17.4 \pm 1.00$ & 0.00 & $14.8 \pm 3.88$ & $19.0 \pm 4.25$ \\
\hline Moderate (Score 2) & $1.10 \pm 0.55$ & $1.35 \pm 0.72$ & $2.90 \pm 1.04$ & $3.00 \pm 1.15$ & $6.15 \pm 1.48$ & 0.00 & $2.50 \pm 1.25$ & $0.00 \pm 0.00$ \\
\hline Severe (Score 3 or more) & $0.00 \pm 0.00$ & $0.67 \pm 0.48$ & $0.30 \pm 0.21$ & $0.00 \pm 0.00$ & $2.30 \pm 1.80$ & 0.00 & $2.50 \pm 1.30$ & $0.00 \pm 0.00$ \\
\hline \multicolumn{9}{|c|}{ Abnormalities among abnormal individuals (\%): } \\
\hline Edemas & $2.19 \pm 1.09$ & $1.10 \pm 0.59$ & $0.94 \pm 0.67$ & $8.67 \pm 1.47$ & $6.87 \pm 2.65$ & 0.00 & $14.4 \pm 6.41$ & $10.3 \pm 5.14$ \\
\hline Axial Skeleton & $1.46 \pm 1.10$ & $8.47 \pm 1.74$ & $4.58 \pm 1.80$ & $7.29 \pm 0.40$ & $12.3 \pm 6.81$ & 0.00 & $1.44 \pm 0.72$ & $7.72 \pm 2.39$ \\
\hline Craniofacial & $2.09 \pm 0.73$ & $0.79 \pm 0.57$ & $2.21 \pm 0.92$ & $2.50 \pm 0.96$ & $1.15 \pm 0.88$ & 0.00 & $1.44 \pm 0.72$ & $0.00 \pm 0.00$ \\
\hline Cardiovascular & $0.00 \pm 0.00$ & $0.80 \pm 0.40$ & $0.40 \pm 0.03$ & $0.00 \pm 0.00$ & $2.30 \pm 1.77$ & 0.00 & $1.00 \pm 0.75$ & $0.00 \pm 0.00$ \\
\hline Yolk sac Malabsorption & $0.60 \pm 0.30$ & $0.00 \pm 0.00$ & $0.37 \pm 0.27$ & $3.43 \pm 2.64$ & $3.24 \pm 1.83$ & 0.00 & $1.50 \pm 1.13$ & $0.00 \pm 0.00$ \\
\hline
\end{tabular}

Letters denote significant differences between experimental group $(\mathrm{P}<0.05)$. 


\section{Table 4}

Relative mRNA expression (Standard Error) of target genes in 96 hpf larvae offspring from parental contamination to three aromatic fractions (PY, BAL, HFO).

\begin{tabular}{|c|c|c|c|c|c|c|c|}
\hline & \multicolumn{3}{|c|}{ PY } & \multicolumn{2}{|c|}{ BAL } & \multicolumn{2}{|c|}{$\mathrm{HFO}$} \\
\hline & $\overline{0.3 \mathrm{X}}$ & $1 \mathrm{X}$ & $3 X$ & $0.3 \mathrm{X}$ & $1 \mathrm{X}$ & $0.3 \mathrm{X}$ & $1 \mathrm{X}$ \\
\hline & $\mathrm{N}=3$ & $\mathrm{~N}=6$ & $\mathrm{~N}=5$ & $\mathrm{~N}=8$ & $\mathrm{~N}=4$ & $\mathrm{~N}=8$ & $\mathrm{~N}=4$ \\
\hline \multicolumn{8}{|c|}{ Housekeeping genes } \\
\hline eefl & 1,122 & 1,038 & 1,039 & 0,912 & 0,879 & 0,905 & 0,944 \\
\hline Bactin & 0,699 & 0,435 & 0,369 & 1,139 & 1,193 & 1,211 & 1,390 \\
\hline gapdh & 1,225 & 1,101 & 1,011 & 1,044 & 0,839 & 0,869 & 0,869 \\
\hline \multicolumn{8}{|l|}{ Detoxification } \\
\hline cyp $1 A$ & $1,211(0.829-1.846)$ & $1,057(0.720-1.465)$ & $0,722(0.471-1.062)$ & $1,013(0.735-1.311)$ & $1,123(0.804-1.687)$ & $1,058(0.749-1.858)$ & $1,142(0.909-1.486)$ \\
\hline$a h r 2$ & $1,075(0.911-1.240)$ & $0,790(0.663-0.929)$ & $0,790(0.689-1.012)$ & $0,984(0.740-1.326)$ & $0,818(0.511-1.321)$ & $0,965(0.781-1.244)$ & $1,064(0.990-1.170)$ \\
\hline$g p \times 4 a$ & $1,051(0.881-1.218)$ & $0,828(0.683-1.034)^{*}$ & $0,895(0.726-1.183)$ & $1,147(0.790-1.608)$ & $1,329(0.995-1.813)$ & $1,075(0.723-1.384)$ & $0,588(0.420-0.758)^{*}$ \\
\hline cat & $1,068(0.833-1.321)$ & $0,901(0.750-1.064)$ & $0,909(0.746-1.122)$ & $0,992(0.893-1.120)$ & $1,074(0.893-1.216)$ & $1,174(0.867-1.616)$ & $1,067(0.908-1.266)$ \\
\hline $\operatorname{sod}(\mathrm{Cu} / \mathrm{Zn})$ & $1,149(1.072-1.344)$ & $0,937(0.774-1.095)$ & $0,982(0.756-1.437)$ & $1,132(0.931-1.308)$ & $1,072(0.832-1.331)$ & $1,328(0.968-1.831)$ & $0,845(0.747-1.980)$ \\
\hline $\operatorname{sod}(M n)$ & $1,203(1.010-1.429)$ & $0,921(0.745-1.164)$ & $0,944(0.706-1.336)$ & $1,142(0.991-1.294)$ & $1,303(1.126-1.551)^{* *}$ & $1,292(1.011-1.574)$ & $1,146(1.030-1.303)$ \\
\hline \multicolumn{8}{|l|}{ Apoptosis } \\
\hline$p 53$ & $1,034(0.836-1.373)$ & $0,765(0.622-1.035)^{*}$ & $0,924(0.547-1.447)$ & $1,468(1.036-2.027)^{*}$ & $1,371(0.979-1.796)$ & $1,607(1.177-2.290)$ & $1,665(1.157-2.246)^{*}$ \\
\hline bax & $1,142(0.906-1.441)$ & $0,972(0.761-1.206)$ & $0,999(0.815-1.321)$ & $1,302(1.075-1.613)^{*}$ & $1,303(1.013-1.694)$ & $1,384(1.106-1.790)$ & $1,421(1.121-1.796)$ \\
\hline
\end{tabular}

Asterisks denote significant changes from respective controls $\left({ }^{*} \mathrm{p}<0.05,{ }^{* *} \mathrm{p}<0.01\right)$. nd : no data available. 


\section{Table 5}

Metabolites compounds (ng. $\left.\mathrm{g}^{-1}\right)$ measured in $120 \mathrm{hpf}$ offspring larvae. Concentration values are means $\pm \mathrm{SEM}$ and values without SEM indicate the compound was identified in one sample.

\begin{tabular}{|c|c|c|c|c|c|c|c|c|}
\hline \multirow[b]{2}{*}{ Metabolites } & \multicolumn{4}{|c|}{ PY } & \multicolumn{2}{|c|}{ BAL } & \multicolumn{2}{|c|}{$\mathrm{HFO}$} \\
\hline & Solvent & $0.3 \mathrm{X}$ & $1 X$ & $3 X$ & Solvent & $0.3 \mathrm{X}$ & Solvent & $0.3 \mathrm{X}$ \\
\hline$\Sigma$ OH-Naphtalenes & $22.9 \pm 5.51$ & $21.07 \pm 1.89$ & $8.47 \pm 1.10$ & $31.2 \pm 7.5$ & $65.0 \pm 13.5$ & $13.0 \pm 3.43$ & $87.0 \pm 13.5$ & $99.0 \pm 13.6$ \\
\hline 2 OH-Biphenyl & $22.7 \pm 7.63$ & $8.27 \pm 0.92$ & $9.22 \pm 1.98$ & $26.37 \pm 4.74$ & $14.4 \pm 5.16$ & $20.1 \pm 4.13$ & $23.1 \pm 0.52$ & 15.7 \\
\hline$\Sigma \mathrm{OH}$-Phenanthrene & 1.05 & $0.54 \pm 0.19$ & blq & blq & 0.2 & blq & blq & blq \\
\hline $3 \mathrm{OH}$-Fluoranthene & blq & blq & blq & blq & blq & blq & blq & blq \\
\hline $1 \mathrm{OH}-P y r e n e$ & $2.23 \pm 0.08$ & $3.61 \pm 1.23$ & $1.97 \pm 0.68$ & $1.65 \pm 0.11$ & $2.07 \pm 0.40$ & blq & 1.05 & $1.74 \pm 0.34$ \\
\hline $1 \mathrm{OH}-\mathrm{Chrysene}$ & blq & blq & blq & blq & blq & blq & blq & blq \\
\hline$\Sigma$ OH-Benzo[a]pyrenes & blq & blq & blq & blq & blq & blq & blq & blq \\
\hline$\Sigma$ OH-HAP & $48.3 \pm 24.2$ & $33.3 \pm 4.19$ & $19.7 \pm 2.43$ & $59.2 \pm 12.2$ & $80.8 \pm 15.2$ & $33.1 \pm 5.98$ & $102.7 \pm 19.5$ & $106.0 \pm 17.9$ \\
\hline
\end{tabular}

No significant differences between experimental group $(\mathrm{P}>0.05)$. Blq : below limit of quantification. 